PROYECTO

Toponimias de Entre Ríos, síntesis y actualización

Exp. $N^{\circ} 134790001$

EQUIPO DE TRABAJO

$\underline{\text { Responsable }}$

Profesor Rubén Isidoro Bourlot

Colaboradores

Geólogo Juan Carlos Bertolini

Arquitecta María Virginia Zabalegui

INFORME FINAL

$\underline{\text { Representante contraparte provincial }}$

Profesor Juan Damián Capdevila

Director del Archivo General de Entre Ríos 


\section{ÍNDICE TEMÁTICO}

Resumen ejecutivo

$\begin{array}{ll}\text { 1. Introducción } & 6\end{array}$

$\begin{array}{ll}\text { 2. Definiciones } & 10\end{array}$

3. Estado de los estudios en la provincia 15

4. Análisis de los topónimos $\quad 17$

4.1 Clasificación de los topónimos 17

$\begin{array}{ll}4.2 \text { Un propuesta de clasificación } & 18\end{array}$

4.2.1 Topónimos vinculados a los cursos de agua 19

4.2.2. Topónimos vinculados con la vegetación 20

4.2.3. Topónimos vinculados con el relieve $\quad 20$

4.2.4. Topónimos vinculados con la ocupación de la tierra 21

4.2.5. Topónimos vinculados la colonización agrícola $\quad 22$

4.2.6. Topónimos vinculados con recursos naturales 22

4.2.7. Los topónimos en lenguas indígenas 23

4.2.8. Evolución de los nombres genéricos de lugares poblados 24

4.2.8. Frecuencia de los topónimos $\quad 25$

4.3. Estadísticas 26

5. Bibliografía y cartografía utilizada $\quad 27$ 
5. 2. Material cartográfico y documental

6. Índice sintético de la toponimia entrerriana

6. 2. Localización

7. Proyecto: Comisión Asesora de Nomenclatura y Toponimia

Bibliografía, documentos y otras fuentes

Anexo I: Cuadros estadísticos 


\section{RESUMEN EJECUTIVO}

El estudio de los nombres de los lugares de un territorio, tal como se define la toponimia, reviste especial interés por sus connotaciones sociales, históricas, políticas, culturales, educativas e incluso económicas.

La toponimia entrerriana nos presenta una riqueza y variedad notables. Hay una persistencia de nombres de origen remoto dado por las comunidades aborígenes, particularmente guaraníticas, tanto en los que señalan accidentes naturales como en los sitios humanizados. Se observa un proceso de superposición de nombres originados en los distintos procesos de poblamiento: indígena, criollo colonial - que en muchos casos combinan un nombre de lengua aborigen con una referencia religiosa -, la colonización agrícola con inmigrantes europeos desde mediados del siglo XIX, y la construcción de las líneas ferroviarias con sus correspondientes asentamientos de nuevos pueblos.

Un nombre geográfico no siempre se constituye en un topónimo. Para que se transforme en topónimo, tiene que haber echado raíces en la tradición del lugar, ser sentido como propio por sus habitantes y defendido como tal. Topónimo, es por lo tanto, la máxima categorización del nombre geográfico, con la comprensión del origen y de su significado.

Este punto de vista es interesante para el análisis de los nombres de los lugares de nuestra provincia, muchos de los cuales no responden a la definición de topónimo en tanto la población no los ha internalizado, en muchas ocasiones son desechados e inclusive caen en el olvido.

No se cuenta en la provincia con una toponimia actualizada, unificada y normalizada. Existen estudios y publicaciones parciales sobre aspectos toponímicos que comprenden diversos tópicos, desde el significado de los vocablos provenientes de 
lenguas indígenas que nombrar los lugares, orografía e hidrografía, hasta índices de nombres de estaciones ferroviarias.

Como resultado del trabajo se presenta un Índice sintético de la toponimia entrerriana que incluye la descripción del significado de 1085 nombres registrados en la Carta de Entre Ríos de 2004 a escala 1:500.000.

El índice contempla los nombres que figuran en la Carta de Entre Ríos correspondiente a la edición 2004, ordenados por departamento y por distrito. De un primer análisis, con apoyo de conocimientos empíricos, cartografía comparativa y documentación auxiliar, se observaron incongruencias en la actualización de la carta, omisiones y disparidad de criterios. Es por ello que se agregan sugerencias de modificaciones.

Simultáneamente se llevó a cabo la localización geográfica de los topónimos mediante coordenadas, y de altitud sobre el nivel del mar.

Como propuesta final se sugiere la creación de una Comisión Provincial Asesora de Nomenclatura y Toponimia que tenga a su cargo el estudio de todas las iniciativas acerca de la imposición de nombres, modificaciones y actualización. 


\section{INTRODUCCIÓN}

El estudio de los nombres de los lugares de un territorio, tal como se define la toponimia, reviste especial interés por sus connotaciones sociales, históricas, políticas, culturales, educativas e incluso económicas. El conocimiento de estos aspectos contribuye grandemente a la consolidación de la identidad de las comunidades del lugar, brindan un aporte a la educación ya que los conocimientos de estos estudios pueden ser apropiados por otras disciplinas como la historia, la geografía, las ciencias biológicas, la literatura, etc. Es un interesante aporte para el desarrollo del turismo, una de las actividades económicas principales de la provincia diseminada en la mayor parte del territorio.

La toponimia entrerriana nos presenta una riqueza y variedad notables. Hay una persistencia de nombres de origen remoto dado por las comunidades aborígenes, particularmente guaraníticas, tanto en los que señalan accidentes naturales como en los sitios humanizados. Sobre esta capa de designaciones se superponen las que se fueron originando con el proceso de poblamiento criollo colonial que en muchos casos combinan un nombre de lengua aborigen, que caracteriza el paisaje natural con la adición de una referencia religiosa. La siguiente etapa, con un considerable impacto en la toponimia, fue el proceso de poblamiento con inmigrantes europeos mediante planes de colonización desde mediados del siglo XIX.

Paralelamente, el trazado de la red ferroviaria que atravesó la provincia de Este a Oeste y de Norte a Sur, la salpicó de nuevos nombres.

La identificación de un lugar se origina en la iniciativa espontánea de la comunidad del lugar, en actos administrativos del estado o de personas o corporaciones con facultades para hacerlo.

En general los nombres que señalan sitios naturales describen las características del lugar: un arroyo llamado "Sauce" indica la presencia de esa especie en la zona. También pueden hacer referencia a las creencias y mitos populares, como son las 
denominaciones de origen religioso: Aldea Protestante, San José, isla del Pillo. En otros casos hacen referencia al origen de los habitantes: Aldea Brasilera, Aldea Alemana. Otros nombres nos informan acerca de actividades económicas como las que tuvieron su origen en algún establecimiento agropecuario (Estancia Grande) o una industria (Pueblo Liebig).

La acción administrativa en la imposición de nombres, a nuestro criterio altera esa armonía natural que la comunidad va creando a través del tiempo. Inclusive, los fundadores de pueblos de la etapa hispánica respetaron la nomenclatura autóctona con el agregado de los términos que refieren al santo patrono de la localidad. Así encontramos: San José de Gualeguaychú, San Antonio de Gualeguay, Etc. Pero en el siglo XIX, tanto desde el estado como de las corporaciones privadas de colonización y de construcción de redes ferroviarias impusieron nombres que en escasas ocasiones respetaron los topónimos lugareños. La Ley 2376 de 1911, en su artículo 5, confirma esa tendencia al establecer que los nombres de los pueblos y colonias podrán ser propuestos por los fundadores. Así proliferaron los homenajes y autohomenajes en los nombres de estaciones y pueblos: Gobernador Basavilbaso, Gobernador Parera, Gobernador Racedo, y así hasta el infinito. Lo mismo las empresas privadas que señalaron su presencia con nombres de sus personeros: Lucas González, por el titular de la empresa Lucas González y Cía. Otro similar es la localidad de Holt que alude al administrador del Ferrocarril de Entre Ríos Follet Holt. También se agregan los nombres de los fundadores privados de colonias y pueblos o de los propietarios de los terrenos: Clodomiro Ledesma, en referencia un propietario; Sosa, por el estanciero Pastor Sosa; Villa Elisa, homenaje a la hija del fundador de la ciudad, etc.

En estos casos se contradice con las recomendaciones de las Naciones Unidas sobre topónimos, que aconseja el respeto a la unicidad del nombre de lugar, cada lugar un único nombre; el respeto a la voluntad de las poblaciones afectadas y el respeto a los nombres autóctonos.

Resulta de interés el estudio de los orígenes y evolución de los nombres, y el grado de apropiación por parte de la comunidad. Tenemos dos casos paradigmáticos como son 
las ciudades de Paraná y Concepción de Uruguay. La primera corresponde al nombre de la parroquia "Nuestra Señora del Rosario de la Villa del Paraná" creada en 1730, aunque durante muchos años los vecinos siguen reconociendo el lugar como "La Bajada". En el caso de Concepción del Uruguay, el nombre impuesto por Tomás de Rocamora en su carácter de fundador demoró décadas en imponerse sobre el topónimo "Arroyo de la China", como se denominaba a núcleo poblacional preexistente.

Encontramos numerosos casos en donde la comunidad no utiliza los nombres establecidos por el voluntarismo fundador. En algunas ocasiones las denominaciones cayeron por falta de uso. Un caso es Villa Dolores, fundada en las adyacencias de la estación Pronunciamiento, que cayó en desuso a favor del nombre de la estación. En otros fueron los propios vecinos quienes solicitaron el cambio de denominación para evitar confusiones con nombres idénticos: Pueblo Racedo dado a Cerrito, General Racedo a una estación del departamento Diamante, y análogo nombre a una localidad del departamento Federación, que por inquietud de los vecinos fue renombrada como Paraje Guayaquil. En este mismo departamento se encuentra el caso de San Jaime de la Frontera, que en 1935 se funda como "Juan B. Arruabarrena", por el propietario de la estancia San Jaime, pero en 1965 los vecinos solicitan volver al nombre de la estación con el agregado del antiguo topónimo "Fronteras". Otros nombres debieron ser modificados por ser demasiado extensos como fue el caso de "Villa Libertador General San Martín" que se cambió por “Libertador San Martín”. Algo similar sucedió con San José de Gualeguaychú, Villa de San Antonio de Gualeguay Grande o San Antonio de Padua de la Concordia que la costumbre transformó en Gualeguaychú, Gualeguay y Concordia respectivamente. Concepción del Uruguay conserva la denominación dada por su fundador Rocamora, pero los vecinos la nombran simplemente "Uruguay".

El presente trabajo pretende, entre otros objetivos, unificar criterios, rescatar los topónimos que persisten en la memoria popular y localizar los sitios a la luz de las nuevas tecnologías y de los cambios naturales y culturales que operan sobre los espacios geográficos. 
El proyecto cuenta con la declaración de interés cultural por parte del Ministerio de Cultura y Comunicación de la provincia que se expidió mediante la resolución $N^{\circ} 481$ del 4 de octubre de 2013 (ver Anexo II). 


\section{DEFINICIONES}

El material analizado nos permite consensuar definiciones y criterios sobre la disciplina que se denomina toponimia. Nos encontramos, en el estudio de la misma, con diversas pautas para su abordaje, según el objetivo que se proponga y desde qué disciplina se la enfoque, y de ahí que su definición difiera.

El “toponimia" deriva etimológicamente del griego tóros (tópos, «lugar») у övo $\alpha \alpha$ (ónoma, «nombre»).

En un trabajo publicado por la página www9.euskadi.net, se define a la toponimia como "la ciencia que estudia los nombres de lugar, tanto los de las divisiones administrativas y de las entidades de población como las de los accidentes geográficos".

En tanto, el Instituto Geográfico Nacional de España, define al topónimo como "Nombre propio con que se designa una entidad topográfica. Se conoce también como nombre geográfico. Con frecuencia está formado por un término genérico y un término específico. Ejs.: Sierra de Segura, Río Pisuerga, Burgos, Alcalá de Henares” ${ }^{1}$.

El topónimo, o nombre de lugar, consta de dos elementos: el elemento genérico que identifica de manera general la entidad geográfica (por ej.: sierra, barrio, río...) y el elemento específico que lo identifica de manera particular (por ej.: Paraná, Ibicuy, Rosario del Tala... $)^{2}$.

\footnotetext{
${ }^{1}$ Toponimia: Normas para el MTN25. Conceptos básicos y terminología Publicación Técnica núm. 42. Dirección General del Instituto Geográfico Nacional, Centro Nacional de Información Geográfica, Madrid, 2003, en http://pendientedemigracion.ucm.es/info/toponim/conceptos.pdf, acceso 17/07/13

${ }^{2}$ http://www9.euskadi.net/euskara toponimia/cas711.htm, Acceso 17/07/13
} 
Los dos elementos deben ser analizados desde un doble punto de vista: el geográfico y el lingüístico. El análisis requiere de distintos especialistas (geógrafo, filólogo, historiador...) que deben trabajar en estrecha colaboración.

Existen unos principios fundamentales sobre la normalización de nombres geográficos establecidos por las Conferencias de las Naciones Unidas, tanto a escala nacional como internacional, que deben constituir un punto de referencia al realizar los correspondientes análisis para intentar fijar y normalizar la toponimia.

Los principios fundamentales adoptados son los siguientes:

1.- El respeto al uso

2.- La unicidad del nombre de lugar, cada lugar un único nombre

3.- El respeto a la voluntad de las poblaciones afectadas

4.- La no traducción de nombres propios

5.- El respeto a los nombres autóctonos ${ }^{3}$.

Para el Grupo de Expertos de las Naciones Unidas en Nombres Geográficos el nombre geográfico es el "nombre propio dado a un accidente sobre la superficie de la Tierra. En general, un nombre geográfico es el nombre propio (una palabra, combinación de palabras o expresión concretas) utilizado sistemáticamente en la lengua para designar un lugar, un accidente o una zona con una identidad reconocible sobre la superficie de la Tierra. Entre los accidentes con nombre se cuentan los siguientes:

1. Lugares poblados (por ejemplo, ciudades, pueblos, aldeas);

2. Divisiones administrativas (por ejemplo, Estados, cantones, distritos, municipios);

3. Accidentes geográficos naturales (por ejemplo, arroyos, montañas, cabos, lagos, mares);

\footnotetext{
${ }^{3}$ http://www9.euskadi.net/euskara toponimia/cas711.htm, Acceso 17/07/13
} 
4. Accidentes geográficos artificiales (por ejemplo, presas, aeropuertos, carreteras);

5. Lugares o zonas no delimitados que tienen una significación local determinada, en muchos casos religiosa (por ejemplo, pastizales, zonas de pesca, lugares sagrados).

En vez de nombre geográfico pueden utilizarse también los términos de nombre propio topográfico o topónimo (término que en su contexto más amplio puede abarcar también nombres extraterrestres, como los asignados a accidentes sobre la superficie de la Luna u otros planetas)" ${ }^{4}$.

En un trabajo titulado Recopilación y representación de la Toponimia de Castilla y León de Hermógenes Perdiguero Villarreal, se consigna que "los objetivos de quienes se adentran en el estudio de los topónimos suelen ser, desde luego, muy distintos: mientras que los lingüistas intentan explicar su significado reconstruyendo el proceso de fijación de un nombre común en topónimo, a los historiadores les interesa poder dejar constancia de personajes, pueblos o acontecimientos anteriores, los geógrafos orientan su mirada al paisaje y a la morfología del terreno y encontrar datos de un pasado áureo es lo que guía, en ocasiones, a quienes bucean en la historia de sus pueblos. Por otro lado, los profesionales dedicados a elaborar catálogos de topónimos o a trabajar en cartografía han de identificar y ubicar adecuadamente cada topónimo, debidamente normalizado por las autoridades competentes" ${ }^{5}$.

Josefa Luisa Buffa, autora de Toponimia Aborigen de Entre Ríos, abunda sobre el tema diciendo que "la toponimia, rama de la lingüística, ofrece gran interés desde el punto de visto histórico, etnográfico, folklórico y sociológico, pues señala las vinculaciones

\footnotetext{
${ }^{4}$ Manual para la normalización nacional de los nombres geográficos, Naciones Unidas, New York, 2007, Departamento de Asuntos Económicos y Sociales, División de Estadística, Grupo de Expertos de las Naciones Unidas en Nombres Geográficos http://unstats.un.org/unsd/publication/seriesm/seriesm 88s.pdf., Acceso 17/07/13.

${ }^{5}$ Universidad de Burgos http://www.fomento.gob.es/NR/rdonlyres/2B5FD4D7-B7DC-4A85-9F6C78AC2A76E63C/71709/ToponiCastillayLeon.pdf - Acceso 17/07/13.
} 
entre el medio social y su contorno. El estudio etimológico de los topónimos aborígenes tiende a determinar las fuentes de las cuales derivan y a explicar el verdadero sentido primigenio, según el análisis de cada uno de los elementos que los integran. Deben sustentarse en argumentos lingüísticos e históricos, para abandonar, de una vez por todas, el empirismo reinante en estudios de esta índole, basados, en la mayoría de los casos, en sugestiones personales, que derivan significaciones fantásticas, cuando no falsas, carentes de lógica” ${ }^{6}$.

El historiador Segura define la Toponimia como "Una rama de la Lingüística que ilustra acerca del significado y del origen del nombre dado a los lugares."7

Según la licenciada Cristina Juliarena de Moretti ${ }^{8}$ se define a la toponimia como "la rama de la ciencia onomástica que tiene por objeto el estudio de los nombres geográficos - tanto naturales como culturales- interesándose en la comprensión de sus orígenes y significados. Conviene aclarar asimismo, que toponimia es también el conjunto de topónimos de un área determinada".

Por otra parte, explica la autora, el topónimo es un nombre propio compuesto por una o más palabras que designa una entidad, accidente o hecho geográfico determinado. El topónimo de acuerdo al sujeto u objeto nominado se clasificará en: orónimo, hidrónimo; referidos a accidentes orográficos o hidrográficos; epónimos al hacer mención a un prócer; fitotopónimos o zootopónimos, en relación con flora o fauna de un lugar.

Advierte que "la denominación individualiza un hecho de la realidad geográfica, respetando y reflejando el espíritu de la lengua y del pueblo que le dio origen, a través de una correcta grafía y una adecuada fonética, que van a identificar al topónimo como único e insustituible".

\footnotetext{
${ }^{6}$ Buffa, Josefa Luisa, toponimia aborigen de Entre Ríos, Editorial de Entre Ríos, Paraná, 1999, pág. 15

${ }^{7}$ Segura, Juan José Antonio, Historia de Nogoyá, Tomo I, Editorial de la Mesopotamia, 1972.

8 Universidad Católica Argentina, Facultad de Filosofía y Letras, Departamento de Historia, Cátedra de Geografía Humana, La cartografía y la toponimia en la investigación histórica, Un enfoque interdisciplinario, Lic. Cristina Juliarena de Moretti, Septiembre 2005.
} 
No obstante aclara que "existirá entonces, un territorio consustanciado con su toponimia, con los nombres que hablan de la historia de los pueblos que habitaron ese espacio. Para esto es necesario recordar que el nombre se transforma en topónimo, cuando ha echado raíces en la tradición del lugar, cuando es sentido como propio por sus habitantes y es defendido como tal. Topónimo, es por lo tanto, la máxima categorización del nombre geográfico, con la comprensión del origen y de su significado. Pero el nombre en sí no representará nada, si no cobra valor a medida que se trasmite una y otra vez, de generación en generación formando parte de la tradición y siendo respetado por las diferentes sociedades en el curso de los tiempos" ${ }^{\prime 9}$.

Este punto de vista es interesante para el análisis de los nombres de los lugares de nuestra provincia, muchos de los cuales no responden a la definición de topónimo en tanto la población no los ha internalizado, en muchas ocasiones fueron desechados e inclusive cayeron en el olvido. Recordamos al pasar un ejemplo de un nombre que nunca alcanzó la categoría de topónimo: en la ciudad de Paraná existe una plaza cuyo nombre fundacional, en 1836, fue Pascual Echagüe, localizada frente a una antigua capilla dedicada a San Miguel Arcángel. Años después, y por cuestiones políticas se sustituyó aquel nombre por el más "decente" de Carlos de Alvear, el que perdura oficialmente hasta hoy. Pero entrevistados viandantes y vecinos acerca del nombre de la plaza, responden espontáneamente que esa es "la plaza San Miguel", sin dudas el verdadero topónimo. Del mismo modo sucede con el pueblo de Gobernador Etchevehere, que a lo largo de casi un siglo se denominó Las Delicias, y en 1985 fue renombrado pero sigue manteniendo en la memoria popular el nombre Delicias, inclusive la carta oficial de 2005 lo denomina así. Y así podríamos continuar con los ejemplos. 


\section{ESTADO DE LOS ESTUDIOS EN LA PROVINCIA}

No se cuenta en la provincia con una toponimia actualizada, unificada y normalizada. Existen estudios y publicaciones parciales sobre aspectos toponímicos que comprenden diversos tópicos, desde el significado de los vocablos provenientes de lenguas indígenas que nombran los lugares, orografía e hidrografía, hasta índices de nombres de estaciones ferroviarias.

Otras de las cuestiones no abordadas son las frecuentes superposiciones e incongruencias de los nombres de algunas localidades que permanecen con múltiples denominaciones. Se da el caso de poblaciones levantadas adyacentes a las estaciones del ferrocarril (durante la gobernación de Racedo, en 1885, se dicta una ley que declara de utilidad pública la expropiación de una legua cuadrada [2.500 Has. de tierra], a cada lado de las estaciones del ferrocarril Entrerriano en el punto designado para las estaciones llamadas intermedias para ser colonizadas) a las que generalmente se les adjudicó un nombre propio, distinto a la estación pero que la costumbre impuso el de esta última (V. Gr.: la localidad de El Pingo, ubicada en la estación homónima, que fue creada como Pueblo San Julián pero nunca adoptó esa denominación o Pueblo San Rómulo que actualmente se denomina El Palenque por el nombre de la estación, o Caseros, fundada como Villa Údine). Otras conservan doble denominación (ejemplo Villa San Marcial Estación Urquiza o General Racedo - Pueblo El Carmen). En otros casos, localidades que durante años tuvieron una denominación y luego por una decisión administrativa se le sustituyó el nombre (el caso de Las Delicias que cambió por Gobernador Etchevehere pero los lugareños siguen denominándola con el antiguo nombre, o el de Villa Libertador San Martín - ubicada en las cercanías de la estación Puiggari - a la que algunos la llaman "la Villa" y otros Puiggari, por el nombre de la estación ferroviaria cercana). Estos son sólo algunos ejemplos de los muchos que encontramos en la provincia. Observamos también 
que Puerto Curtiembre, una localidad sobre el río Paraná que se constituyó como junta de gobierno con el nombre formal de Pueblo General San Martín.

En la cartografía se detectan estas inconsistencias y otras vinculadas a la escritura de los nombres para lo cual se hace necesario unificar criterios.

También nos encontramos con nombres de origen desconocido o dudoso, como, a modo de ejemplo, son los casos de las localidades de Sauce de Luna y Ramírez, el arroyo Pospos, entre otros. Es probable que el verdadero origen y significación del topónimo, se ha perdido en la nebulosa de los tiempos.

Con respecto a la toponimia orográfica e hidrográfica se observan frecuentes errores o contradicciones en la escritura al comparar las distintas documentaciones y publicaciones, lo que es necesario conciliar. 


\section{ANÁLISIS DE LOS TOPÓNIMOS}

\subsection{CLASIFICACIÓN DE LOS TOPÓNIMOS}

Un buen estudio de la toponimia exige adoptar criterios de clasificación. Damián Gustavo Rondán puntualiza que "hay muchos criterios para realizar una clasificación de los topónimos. Se ha elegido el más abarcativo y el que ayudará con más acierto, a estructurar este trabajo de investigación".

Siguiendo a este autor, los topónimos se clasifican en naturales y culturales.

Los naturales se dividen en tres grupos:

a) Fitotopónimos: designación a un lugar de la vegetación autóctona o alóctona, ejemplos: arroyo Las Tunas, distrito Sauce, arroyo Los Berros, distrito Tala, etc.;

b) Zootopónimos: las designaciones se refieren a los animales, que generalmente representan la fauna originaria de los lugares nombrados, ejemplos: Puerto Víboras, estación Las Garzas, Cañada Avispas, Arroyo de las Vizcachas, etc.;

c) Fisiotopónimos: designan una característica física o paisajística del lugar, ejemplos: Arroyo Seco, Oro Verde, Arroyo Rambloncito, etc.

Según su origen, circunscripto a la realidad entrerriana, el autor citado propone la siguiente clasificación: 1) Topónimos de origen indígena; 2) Topónimos de origen colonial o hispánico; 3) Topónimos de origen inmigrante; 4) Topónimos cuyo origen se vincula con el ferrocarril; 5) Otros casos: existen casos de poblaciones de origen espontáneo, o que sin seguir ningún patrón, fueron desarrollándose poco a poco ${ }^{10}$.

Buffa clasifica los topónimos, en este caso dedicada al estudio de los de origen aborigen exclusivamente, en: 1) Toponimia aborigen y 2) toponimia de doble dimensión

\footnotetext{
${ }^{10}$ Damián Gustavo Rondán, Toponimia del departamento Paraná, Entre Ríos, Argentina. Trabajo presentado en las II Jornadas de Toponimia en la U.N.N.E., Resistencia, Chaco - 1994. Aumentado en 2007.
} 
(cuando se trata de nombres compuesto por términos en lengua aborigen y castellana). A los de origen aborigen los clasifica a su vez en: 1) Biogeográficos; a) Fitogeográficos; b) Zoogeográficos. 2) Fisiogeográficos. 3) Antropogeográficos. 4) Hispoanoguaraníes.

Juan José Antonio Segura clasifica los topónimos en:

a) Nombres impuestos por los indígenas;

b) Nombres de la naturaleza para referirse a los que surgen de los accidentes y cualidades naturales; y

c) Nombres históricos, dados por los ocupantes de las tierras, refiriéndose a la ocupación española. ${ }^{11}$

Los criterios citados nos permiten orientarnos en el análisis de la toponimia ajustada a la última versión publicada de la carta oficial provincial ${ }^{12}$.

\subsection{UNA PROPUESTA DE CLASIFICACIÓN}

En el presente trabajo se llevó a cabo la identificación de los topónimos en base a dos criterios de clasificación.

Según un primer criterio se clasifican los nombres en:

a) Topónimos vinculados a los cursos de agua

b) Topónimos vinculados con la vegetación

c) Topónimos vinculados con el relieve

d) Topónimos vinculados con la ocupación de la tierra

e) Topónimos vinculados la colonización agrícola

f) Topónimos vinculados con recursos naturales

g) Los topónimos en lenguas indígenas

El segundo criterio clasifica los nombres en:

\footnotetext{
${ }^{11}$ Segura, Juan José Antonio, Historia de Nogoyá, T. I: desde los orígenes hasta 1821, Paraná, 1972.

${ }^{12}$ Carta de Entre Ríos, Dirección de Catastro, 2004, escala 1:500.000.
} 
a) Fitotopónimos: originados en la vegetación del lugar, tanto autóctona como exótica.

b) Zootopónimos: originados en la fauna del lugar y otros relacionados con animales domésticos.

c) Fisiotopónimos: originados en los accidentes geográficos, el paisaje y los recursos naturales.

d) Antropotopónimos: originados en nombres de personas relacionadas con acontecimientos históricos, en general impuestos por la autoridad administrativa, y de vecinos y ocupantes de las tierras.

e) Hagiotopónimos: originados en nombres de santos y en la terminología de carácter religioso.

\subsubsection{Topónimos vinculados a los cursos de agua}

Los corrientes de agua y sus componentes dieron origen a numerosos topónimos como lo señala el citado Segura. Así las "puntas" señalan lugares situados en las nacientes o vertientes de las mismas. Por ejemplo: Puntas del Gualeguaychú, Punta del Sauce. Las afluencias o desembocaduras se denominan en la toponimia como "barra", así "barra del Nogoyá". Los lugares donde se puede pasar con cabalgaduras o carruajes se denominan "pasos", que se conservan en la actualidad en numerosos lugares como Paso Telégrafo, Paso de la Laguna o Paso Paysandú. Muchos de estos lugares hoy están salvados puentes. En el departamento Concordia se distingue el histórico "paso" Hervidero, sobre el río Uruguay.

Las tierras cercanas o ribereñas de ríos y arroyos figuran como "costas" o "bandas". Así la antigua denominación de Paraná como Bajada de la otra banda del Paraná, Banda Oriental del Uruguay, Costa del Vizcaíno o Costa Grande que es el nombre de un distrito del departamento Diamante. Al respecto dice el historiador Oscar Trossero que "el nombre Costa Grande se debe a que los viajeros que se acercaban por entonces Diamante, navegando aguas arriba el Paraná, repentinamente se encontraban con las 
barrancas, que seguramente llamarían su atención. No se podría negar entonces, quien las avistara, con asombro exclamar a sus compañeros, algo así como...'vean la costa grande...', o alguna expresión similar que contuviera esos vocablos" ${ }^{13}$. En el departamento Gualeguaychú se encuentran los distritos Costa Uruguay Norte y Costa Uruguay Sur.

Los espacios encerrados entre dos o más cursos de agua desde muy antiguo se denominaron "ricón" y "horqueta", como Rincón de Nogoyá, Rincón de Urquiza. Estas rinconadas servían para mantener controladas las tropas ante la inexistencia de alambradas y por eso aparecen otros topónimos similares como "encierra", "chiqueros", "brete".

Los bordes de los ríos y arroyos son utilizados para nombrar lugares como las "barrancas", así arroyo Barrancoso, y las prominencias costeras como Punta Gorda en la actual Diamante o Punta de Piedra como se nombra a Paraná en el mapa de de América del Sur de Thomas Kitchin, fechado en 1787, y las "bajadas" de las barrancas hacia los ríos como el antiguo nombre de Paraná: La Bajada o el actual barrio de la ciudad denominado Bajada Grande.

\subsubsection{Topónimos vinculados con la vegetación}

Las zonas cubiertas de vegetación arbustiva y arbórea se denominan "montes" y en algunos casos "selvas", aunque este último es un término impropio para la flora entrerriana. Así tenemos la denominada Selva del Montiel, antiguamente denominada más propiamente Montes de Montiel. Los comienzos de los montes se los indicaba como "puntas" y los bordes como "orillas". Las "picadas" eran los caminos abiertos en el monte y las "isletas" eran grupos o bosquecitos aislados de arbustos y árboles. Por ejemplo el arroyo Isletas en el departamento Federal y el distrito del mismo nombre en el departamento Diamante.

\footnotetext{
${ }^{13}$ Trossero, Oscar O. R., Costa Grande... historias del pago, Editorial de Entre Ríos, Paraná, 2001.
} 


\subsubsection{Topónimos vinculados con el relieve}

Las elevaciones características de la provincia, denominadas "lomadas" y las "colinas", forman parte de la toponimia, a veces con la denominación impropia de "cuchilla", tal vez por su similitud con las cuchillas del territorio de la República Oriental del Uruguay. Los nombres más conocidos son las "lomadas o cuchillas de Montiel y Grande". También se refieren al relieve topónimos como el "Cerro de la Matanza", como era conocida antiguamente Victoria, la localidad de Cuchilla Redonda, en el departamento Gualeguaychú, el distrito Cuchillas en el departamento Gualeguay y el "Cerro de la Esperanza" como suele llamarse localmente a Libertador San Martín. O a Victoria, denominada "la ciudad de las Siete Colinas".

Otros nombres vinculados al relieve son: Médanos, una localidad y distrito en Islas del Ibicuy y otro distrito en el departamento Gualeguay, debido a la abundancia de arena en la zona que se acumula en forma de dunas; o Albardón, un distrito en el departamento Gualeguay en referencia a los albardones o bordes elevados existentes en la zona, típicos

de los territorios del delta. El Ramblón, una colonia situada entre los arroyos Quebracho y Grande en el departamento Paraná y Ramblones, un paraje en el departamento Paraná y dos arroyos en el departamento Federal, hacen alusión a las hondonadas donde corren aguas pluviales que luego, por la erosión, quedan cubiertos de arena.

\subsubsection{Topónimos vinculados con la ocupación de la tierra}

En el transcurso del tiempo se observan cambios en los topónimos referidos a los parajes y a cursos de agua de menor importancia que suelen identificarse con los nombres de los propietarios de la tierra y son modificados en función de los traslados de titularidad. No obstante hay casos donde persiste la doble nomenclatura hasta la actualidad. Algunos ejemplos: los arroyos del Cordobés y Urquiza. En el siglo XVIII se denominaba "del Cordobés" a toda la extensión del arroyo, incluyendo el actual Urquiza: El origen del nombre está registrado en un reclamo de propiedad que en 1785 hace Juan 
José Castro oriundo de Córdoba, de una parcela sobre el citado arroyo "que así llaman por la patria del solicitante". Rocamora en su informe de 1782 también lo nombra como Flores o Largo. Posteriormente, y a partir de la adquisición de tierras por parte de José de Urquiza, un tramo del arroyo pasa a llamarse "Urquiza". Como mencionamos más arriba otros conservan la doble denominación como el Molino o Itapé en el departamento Uruguay, el Hondo o de la Cruz en el departamento Paraná, o el Ciudad o Santa Rosa en el departamento Colón. ${ }^{14}$

\subsubsection{Topónimos vinculados la colonización agrícola}

Otro proceso de la nomenclatura es el que produjo las distintas corrientes colonizadoras del siglo XIX y XX, en particular la colonización agrícola. En este caso se observa una profunda alteración de los topónimos preexistentes por la incorporación de nombres vinculados con los lugares de origen de los pobladores, en el caso de las aldeas de alemanes del Volga en particular. Por ejemplo los nombres de las aldeas Spatzenkutter, Mariental, Brasilera, Marienfeld, o colonia Alemana y la judía Novibuq. En otros casos los nombres se vinculan a los credos religiosos como Aldea Protestante, algunas judías y las numerosas que llevan nombres de santos de la Iglesia Católica.

Resulta curioso que algunas colonias judías conserven nombre de santos católicos como San Gregorio en el departamento Villaguay o Colonia San Antonio en el departamento Colón.

Encontramos nombres repetidos con las adiciones relacionadas con la ampliación de colonias y pueblos, como son los denominados "ensanches": Primer ensanche de Mayo y Quinto Ensanche en el departamento Uruguay. El aditamento de "nuevo o nueva", como son los vemos en las colonias Nueva al Norte y Nueva al Sur en el departamento Uruguay

\footnotetext{
${ }^{14}$ Cfr. Pérez Colman, César Blas, Historia de Entre Ríos, Época colonial (1520 - 1810), T I. Imp. de la Provincia, Paraná, 1937.
} 
y Colonia Nueva en el departamento Paraná. O Pueblo Nuevo, nombres de respectivos barrios de Basavilbaso y Gualeguaychú.

\subsubsection{Topónimos vinculados con recursos naturales}

Una de las características observadas en lo topónimos está relacionada con recursos naturales. La actual ciudad de Paraná en un mapa de Miguel Antonio Ciera, de 1758, figura como La Calera, lo que da una idea de lo que significaban como riqueza los yacimientos de cal. Así otra localidad del departamento La Paz se denomina Piedras Blancas en alusión a los yacimientos de yeso, lo mismo que un paraje, un arroyo y un distrito del mismo departamento se denominan Yeso. En Victoria barrio Quinto Cuartel también es conocido como de las Caleras.

\subsubsection{Los topónimos en lenguas indígenas}

Otra cuestión que merece un análisis detenido es el de los nombres que se originan en las lenguas indígenas puesto que existe disparidad de interpretaciones. Benjamín Solari, citado en un trabajo por Gaspar L. Benavento ${ }^{15}$, sostiene que el guaraní "realiza la toponimia de su medio o escenario, de manera gráfica y, casi diría, descriptiva. Clasifica la flora y la fauna con tendencias naturalistas casi perfectas: en unos casos, por los caracteres externos, y, en otros, por las propiedades que le son propias."

Otro autor, el incansable investigador Antonio Serrano, dice que “...La toponimia entrerriana es rica en nombres guaraníes y esto pudiera tomarse como una consecuencia del predominio del guaraní dentro de su territorio, lo que no es así.

"Los guaraníes, desde mucho antes de la conquista, sirvieron de intérpretes y guía. Primero de los núcleos no guaraníes, después de los conquistadores, de las autoridades coloniales, de los jesuitas y también de los charrúas, quienes aprendieron su idioma como

\footnotetext{
${ }^{15}$ Benavento, Gaspar L., El guaraní en Entre Ríos, Instituto Amigos del Libro Argentino, Bs. As, 1962.
} 
una lengua de trato. Así influyeron en las designaciones toponímicas guaraníes tan frecuentes en nuestra provincia” ${ }^{16}$

Cabe advertir que muchos de los nombres de lugares con palabras de lengua guaraní no son los originales impuestos por los antiguos habitantes del lugar sino por los conquistadores que, por tener un leguaje con escritura, lo registraron según su criterio y en muchos casos alterando las denominaciones originales. Tenemos los topónimos que designan a nuestros grandes ríos como Paraná, Uruguay, Gualeguay que fueron escritos de diversa manera en la cartografía y en otros documentos hasta llegar a consolidarse. Encontramos para Uruguay los términos Huruguay, Oroy, Urualt y Uruguai. Para Gualeguay encontramos Yaguarí, Curueguay, Guareguá o Iguiguití, Guaiguiti, y para Gualeguaychú los términos Guaguachuy, Yaguarí Guazú, Malaguay y Yaguariguaer. Lo mismo podemos decir cuando observamos los nombres de cursos de agua que llevan la designación de animales y plantas en lengua guaraní. Es muy probable que el topónimo fuera impuesto por los ocupantes españoles y no por los habitantes prehispánicos, salvo algunos casos muy puntuales como Tatutí que significa "río donde abundan los tatúes", lo que denota que quién lo llamó así conocía la lengua autóctona. Son frecuentes, en los estudios sobre toponimia, las interpretaciones dudosas como es el caso de Sarandí, nombre de una docena de arroyos, que según Josefa L. Buffa, se compone de sara, "arbustillo que crece a orillas del agua y es fácilmente movido por la corriente", más ndi, "sufijo que expresa abundancia, conjunto" (sería "arroyo de los saras"). Es probable que el nombre de este y los otros arroyos se refieran al árbol, en singular, porque sería una extraña coincidencia que a todos se los hubiera nombrado con el plural sarandí y no encontremos ningún topónimo con el singular sara. Nos permitimos discrepar con esta interpretación de la reconocida lingüista.

\subsubsection{Evolución de los nombres genéricos de lugares poblados}

${ }^{16}$ Idíd. 
Los nombres de los lugares poblados fueron cambiando a través del tiempo. En la época colonial, antes de las fundaciones de Tomás de Rocamora, se conocían los lugares poblados, generalmente dispersos, como "pagos". El proceso fundacional planificado por parte de las autoridades españolas llega a Entre Ríos con Rocamora en 1783. A partir de ese momento se fundan "villas" que era una de las categorías de núcleos urbanos autónomos, junto con las "ciudades". Esta terminología se siguió utilizando a lo largo del siglo XIX. Con el proceso de colonización se sumaron otras categorías de poblaciones, tanto concentradas como dispersas. Aparece las categorías de "pueblo", para los centros de población planificados en la segunda mitad del siglo XIX, "colonia" para los asentamientos dispersos y las "aldeas" que identifican casi en exclusividad a los pequeños centros poblados formados por inmigrantes alemanes del Volga. En numerosos casos ese término genérico quedó incorporado al nombre propio como "Villa Elisa", "Colonia Nueva”, "Pueblo Brugo" o "Aldea Alemana".

\subsubsection{Frecuencia de los topónimos}

Entre los nombres más frecuentes hallamos el topónimo "sauce" y derivados como "saucecito" y "los sauces" - se conocen en la provincia 60 arroyos y 4 lagunas con ese

nombre -, "guayabo" le sigue en frecuencia, "sarandí" se repite en 12 arroyos y con el nombre de "quebracho" se conocen otros 12 cursos de agua. Este último es un caso muy particular ya que el quebracho es una especie muy rara en la provincia, en tanto, como lo observa Ibáñez, se conocen sólo dos topónimos relacionados con del "ñandubay", árbol tan significativo en la flora entrerriana: un pequeño arroyo y el balneario El Ñandubaysal cerca de la ciudad de Gualeguaychú. Otros fitotopónimos frecuentes son "espinillo", "chilcas", "ombú", "achiras" y "tunas".

\subsection{ESTADÍSTICAS}


Con el objeto de presentar gráficamente las características de la toponimia se incorporan en el Anexo I: Cuadros estadísticos de los topónimos, el detalle según el motivo que dio origen a los nombres. Para su elaboración consideraron cuatro grupos:

- Fitotopónimos: originados en la vegetación del lugar, tanto autóctona como exótica.

- Zootopónimos: originados en la fauna del lugar y otros relacionados con animales domésticos.

- Fisiotopónimos: originados en los accidentes geográficos, el paisaje y los recursos naturales.

- Antropotopónimos: originados en nombres de personas relacionadas con acontecimientos históricos, en general impuestos por la autoridad administrativa, y de vecinos y ocupantes de las tierras.

- Hagiotopónimos: originados en nombres de santos y en la terminología de carácter religioso. 


\section{BIBLIOGRAFÍA Y CARTOGRAFÍA UTILIZADA}

\subsection{BIBLIOGRAFÍA}

El equipo trabajó sobre la diversa bibliografía disponible, actual e histórica.

Como se indica en el apartado anterior, no existe una toponimia entrerriana completa y actualizada, y las que hay son ediciones muy antiguas y parciales. Entre otros trabajos consultados mencionamos los estudios realizados por César Blas Pérez Colman en su "Historia de Entre Ríos, Época colonial" y otros, así como "Significado de la nomenclatura de las estaciones ferroviarias de la República Argentina" editado en 1942 y que trata solamente de los nombres de las estaciones y el "Diccionario Geográfico Argentino" del Instituto Geográfico Militar, una edición de 1954, que consta de un catálogo completo de lugares pero sin la explicación del origen y significado de los topónimos. En 1971 Francisco Ibañez, publicó su "Toponimia de Entre Ríos. La Tierra, el hombre y los hechos", que describe una selección de topónimos naturales. Por otra parte el trabajo de Josefa Luisa Buffa, "Toponimia aborigen de Entre Ríos", se refiere exclusivamente a los nombres de origen indígena. Recientemente se realizaron trabajos de toponimia parciales, como Damián Gustavo Rondán: "Toponimia del departamento Paraná" y el de Margarita Grimaux de Gil, "Toponimia de Entre Ríos" de 1988 aunque muy parcial.

\section{2. MATERIAL CARTOGRÁFICO Y DOCUMENTAL}

También se recopiló información a partir del análisis del material cartográfico y documental obrante en archivos, bibliotecas y museos de la provincia.

El material documental existente en el Archivo General de Entre Ríos nos permite determinar el origen de algunos nombres impuestos en el acto de fundación de pueblos, 
estaciones ferroviarias y colonias. Se analizó la Recopilación de Leyes y Decretos de Entre Ríos, documentos pertenecientes a la Series Tierras, Estadísticas y Censos y Municipalidades del fondo Gobierno, y a la serie Educación del Fondo Hacienda, todos pertenecientes al Archivo General de Entre Ríos. La cartografía es otra fuente de información sobre el origen y evolución de los nombres. Se llevó a cabo recopilación de información de las cartas y planos topográficos y catastrales pertenecientes al fondo Geodesia y Topografía de la Dirección de Catastro de la Provincia, y cartografía histórica de diverso origen obrante en el Archivo General de Entre Ríos, y la cartografía antigua de la región a partir de la ocupación europea.

También se consultaron los archivos de la Dirección General de Relaciones Municipales y la Dirección de Juntas de Gobierno. 


\section{6. ÍNDICE SINTÉTICO DE LA TOPONIMIA ENTRERRIANA}

En el Anexo III, en cuerpo separado, se presenta el Índice sintético de la toponimia entrerriana que incluye la descripción del significado de 1085 nombres registrados en la Carta de Entre Ríos de 2004 a escala 1:500.000, a partir de las citadas toponimias de Enrique Udaondo, "Significado de la nomenclatura de las estaciones ferroviarias de la República Argentina" de 1942, del "Diccionario Geográfico Argentino" publicado por Instituto Geográfico Militar en 1954, y complementado con trabajos parciales y específicas de más reciente publicación que se detallan en la bibliografía, y los testimonios recopilados durante el trabajo de campo. Para cada entrada se especifica el nombre específico y el término genérico y cuando corresponde, los nombres alternativos. A continuación figura la localización geográfica, la descripción del topónimo, el significado del nombre. En los casos donde se observan divergencias entre los autores se consignan las distintas opciones con la correspondiente cita del autor o informante. Cuando corresponde se realiza un seguimiento de la evolución histórica de los nombres del lugar, a partir de la bibliografía, de la cartografía y de las fuentes documentales. También se adopta el criterio de incorporar como información los acontecimientos de carácter histórico que se vinculan con el lugar, lo que le agrega significado. Para la determinación de los nombres de origen indígena, mayoritariamente guaraní, se consultaron, entre otros trabajos, los de Josefa Luisa Buffa, Gaspar L. Benavento, Miguel Raúl López Bréard, Florencio López, y José Miguel Irigoyen.

El índice se confeccionó respetando los nombres que figuran en la Carta de Entre Ríos correspondiente a la edición 2004, ordenados por departamento y por distrito. De un primer análisis, con apoyo de conocimientos empíricos, cartografía comparativa y documentación auxiliar, se observan incongruencias en la actualización de la carta, 
omisiones y disparidad de criterios. Es por ello que se agregan sugerencias de modificaciones. A modo de ejemplo mencionaremos algunas observaciones.

En la carta 2004 figuran desactualizados los nombres de localidades que por disposiciones oficiales cambiaron de designación. Por caso el pueblo y estación Gobernador Etchevehere, departamento Diamante, que desde 1985 se denomina así, sigue figurando con su antiguo nombre "Las Delicias". En la carta del Instituto Geográfico Militar figura con el nombre correcto. Otro caso notable es el comentado más arriba de Colonia Racedo, departamento Concordia que en 1968, por pedido de los vecinos, cambió el nombre a Paraje Guayaquil, pero en la carta sigue con la vieja denominación. En este caso la carta del IGN también conserva el antiguo nombre.

En otros casos la carta omite nombres significativos de nuevos lugares como la de poblaciones que surgieron en los últimos años, como es el caso de Pueblo General Belgrano, municipio autónomo de unos 2.000 habitantes, vecino a la ciudad de Gualeguaychú, Colonia Ensayo, en el departamento Diamante o Colonia San Cipriano, departamento Uruguay, con un centro concentrado de población y Junta de Gobierno.

Se observan lugares referenciados incorrectamente a nuestro criterio, como estaciones o poblaciones que en la actualidad no cumplen con esa función. Lo mismo sucede con los denominados "pasos" que en un tiempo fueron vados en los arroyos, desde hace años en desuso o sustituidos por puentes. Hay errores en los nombres, algunos sutiles y otros significativos, como es el caso de "Paso Laguna" que figura en la carta y el correcto es "Paso de la Laguna".

En el caso de Palo a Pique, departamento Feliciano figura como una localidad sobre la Ruta provincial $N^{\circ} 1$ y no es más que una estación abandonada de la antigua línea ferroviaria entre La Paz y Feliciano. El paraje integra un centro rural de población denominado Las Mulitas que no figura como tal en la carta.

Existe una evidente confusión en la utilización de signos cartográficos lo que dificulta la lectura. Como ejemplos comentamos que el correspondiente a "paraje" 
identificado gráficamente como " $\therefore$ " dado a lugares que no corresponderían a esa categoría, como el caso de Sauce Pinto, que figura como "paraje" y es una pequeño centro poblado, lo que induce a confusión. Otra caso es "Colonia Hughes" que no está referenciada como centro de población.

Por otra parte se observan lugares señalados gráficamente como "estación" del ferrocarril o centro de población cuando hoy no existe población concentrada, y sólo persisten las ruinas de la estación.

Nombres genéricos utilizados en la carta de Entre Ríos 2004

- Lugares poblados: Pueblo, Villa, Aldea, Colonia, Paraje

- Divisiones administrativas: Departamento, Distrito, Sección,

- Accidentes geográficos naturales: Ríos, Arroyo, Cañada, Laguna, Paso, Riacho, Isla

- Accidentes geográficos artificiales: Ruta, Camino, Ferrocarril, Estación del ferrocarril, Embarcadero, Apeadero, Puerto, Puente, Túnel, Complejo Hidroeléctrico, Conexión vial, Complejo Ferrovial, Parque Nacional,

- Lugares o zonas no delimitados que tienen una significación local determinada: INTA, Escuela Alberdi.

\section{2. LOCALIZACIÓN}

Simultáneamente se llevó a cabo la localización geográfica de los topónimos mediante coordenadas, y de altitud sobre el nivel del mar, para lo cual se establecieron los siguientes criterios:

Los cursos de agua se localizan en su desembocadura.

Los centros de población se localizan tomando puntos significativos: el centro de la plaza principal, en las localidades que las poseen. En otros casos, cuando no existe una plaza central se toma como referencia la estación ferroviaria o un edificio público como la Municipalidad, una iglesia o una escuela. 
Para los parajes o localidades rurales dispersas se toma como referencia una capilla, escuela u otra edificación significativa. En el caso de no hallarse una referencia de este tipo se localizan las coordenadas en el lugar equidistante según surge del trabajo en terreno.

Los nombres se presentan ordenados por distrito y departamento a los que se les va agrega la correspondiente referencia en base a la bibliografía consultada, los documentos y al aporte de las personas entrevistadas.

En el proceso de localización se constataron diferencias en la ubicación de los lugares respecto de lo graficado en la carta 2004 debido a múltiples factores que se enumeran a continuación:

La carta 2004 fue elaborada utilizando datos obtenidos con tecnologías que hoy están ampliamente superados con una considerable ganancia en precisión. Para su confección se utilizaron datos del ex Instituto Geográfico Militar y de imágenes satelitales de las décadas del 70 y 80 que no ofrecían la misma calidad de las actuales.

Los cursos de agua sufrieron una deriva visible producto de la colmatación natural y por los procesos de erosión de los suelos por deforestación y laboreo agrícola, represamiento y canalizaciones, lo que repercute en el ensanchamiento de cauces, el cambio del curso y de los sitios de sus desembocaduras, que se toman para su localización.

En las zonas de islas, los afluentes de los arroyos principales y secundarios del Uruguay y/o Paraná en el bajo delta, en particular en el departamento Islas, pueden variar por la influencia de los mismos y por las sudestadas, por lo tanto, su embocadura o desembocadura pueden sufrir cambios notables. La ubicación de las desembocaduras son aleatorias según las condiciones citadas. Cabe consignar aquí, que las características morfológicas son heredadas de paleocanales de mareas que influyeron a partir de los 8000 años antes del presente. La antigua topografía, como fondo de mar en forma de canales de marea, hoy tiene características fluviales que van transgrediendo las antiguas 
paleoformas marinas y repercuten sobre el paisaje. Estas manifestaciones fluviales ambientales se ven acentuadas a su vez por las diferentes obras de artes realizadas en esta zona (puentes, canales, caminos, terraplenes, etc.) que ha infringido la acción del hombre (acción antrópica). A modo de ejemplo al azar: el arroyo Baltazar es una muestra típica que relaciona los puertos Ibicuy y Constanza pasando a ser un afluente variable del río Paranacito según la cartografía oficial utilizada para este trabajo.

En todo el territorio provincial se observa la incidencia de las numerosas obras de infraestructura que alteran la localización de puentes, pasos y cursos de agua, respecto de la señalada en la carta de 2004.

Igual situación se observa con la desaparición de trazas de las líneas ferroviarias producto de su desactivación, y como consecuencia la de las estaciones, apeaderos y parajes poblados. Esto dificulta la localización de los sitios que aún figuran en la carta 2004 ya que no existen referencias sobre el terreno.

El índice se complementa con los recortes de las cartas departamentales con la indicación expresa de las modificaciones que a modo de sugerencia se incorporan. 


\section{PROYECTO: COMISIÓN ASESORA DE NOMENCLATURA Y TOPONIMIA}

Como propuesta final se sugiere la creación de una Comisión Provincial Asesora de Nomenclatura y Toponimia que tenga a su cargo el estudio de todas las iniciativas acerca de la imposición de nombres, modificaciones y actualización. La misma deberá tener un carácter amplio y participativo. Para su constitución se propone una convocatoria a distintos organismos e instituciones de la provincia y de entidades locales. Se estima que deben integrarla representantes del Archivo General de Entre Ríos, el Museo de Ciencias Naturales y Antropológicas "Prof. Antonio Serrano", el Museo Histórico "Martiniano Leguizamón, la Dirección de Catastro, Ministerio de Turismo, organizaciones no gubernamentales vinculadas al patrimonio, las ciencias históricas, geográficas, etc. y en cada caso representantes alternos de las comisiones de nomenclatura de las localidades involucradas. La comisión debería ser de consulta obligatoria en el caso de la imposición de nombres de lugares y obras de infraestructura, modificaciones y cambios. Se expediría mediante recomendaciones o dictámenes.

La comisión debería adoptar los principios fundamentales sobre la normalización de nombres geográficos establecidos por las Conferencias de las Naciones Unidas, citado up supra, para intentar fijar y normalizar la toponimia provincial, y que son los siguientes:

1.- El respeto al uso

2.- La unicidad del nombre de lugar, cada lugar un único nombre

3.- El respeto a la voluntad de las poblaciones afectadas

4.- La no traducción de nombres propios

5.- El respeto a los nombres autóctonos.

Prof. Rubén Bourlot

Paraná, febrero de 2014 


\section{Bibliografía, documentos y otras fuentes}

\section{Bibliografía édita e inédita}

- Acosta, Víctor Hugo, Diamante y su toponimia. Diamante, Municipalidad, 1993. (Cuaderno de Cultura 1)

- Almará, José Antonio, Historia de diez pueblos entrerrianos, Bando de Entre Ríos, Paraná, 1989.

- Anadón, Carlos A. y Murature de Badaracco, María del Carmen, Historia de La Matanza, Victoria, 1985.

- Benavento, Gaspar L. El guaraní en Entre Ríos, Instituto Amigos del Libro Argentino, Bs. As. 1962. (Biblioteca Archivo 1579)

- Brumatti, Ricardo Luis, Aniversario de Strobel, en El Diario, Paraná, 21 de febrero de 2010.

- Buffa, Josefa Luisa, Toponimia aborigen de Entre Ríos, Buenos Aires, Universidad Nacional de La Plata, 1969

- Castro, Antonio P. Crónica regionales entrerrianas, Edit. Guillermo Kraft, Bs. As., 1950.

- Cerrudo, Luis Ángel, El Palacio San José, casa del general Urquiza, Dunken, Bs. As. 2010.

- Chaves, Claudina, Antecedentes históricos Sir Leonard, departamento La Paz, Entre Ríos, Junta de Gobierno (Gestión 2007-2011). Inédito.

- Chudnovsky, José, Pueblo Pan, ed. Losada, Bs. As., 1967.

- Cooke, Norma y de Santiago, Susana, Por los senderos de la memoria. Narrativa histórica de Arroyo Barú, Birkat Eloim, Colón, 2011. 
- Cuadernos de Estudios Regionales, № 2, 1982, Instituto Regional de Investigaciones Científicos - Culturales, Concordia.

- Degano, Aníbal Edgardo, Pueblo General Racedo, más de 100 años de desarrollo, Maci, Santa Fe, 1998.

- Diccionario Geográfico Argentino, Tomo I: Entre Ríos, Corrientes y Misiones, Ejército Argentino, Instituto Geográfico Militar, Bs. As. 1954.

- Domínguez Soler, Susana T. P. de, Entre Ríos y viñas, Instituto Urquiza de Estudios Históricos, Bs. As. 2000.

- Fernández, Miguel Ángel, San José de Feliciano, un pago con historia I, De los Cuatro Vientos, Bs. As., 2006.

- Fondo Comunal, cincuenta años de vida (1904 - 1954). Fondo Comunal, Villa Domínguez, 1957.

- Fray Mocho (José S. Álvarez), Un viaje al país de los matreros. Ediciones Estrada, Bs. As., 1968.

- Gallay, Omar, Esperanza, corazón y tierra. Narrativa histórica de la colonia San Cipriano, El Autor, C. del Uruguay, 2008.

- García, Alfredo Eduardo, La Rinconada. Crónicas del Ibicuy en el ayer, Ediciones del Clé, Paraná, 2013.

- Garra, Lobodón (Liborio Justo), Río abajo (El drama de los montes y los esteros de las islas del Ibicuy), Colección Tatú, Ed. Schapire, Bs. As., 3 Ed. 1968.

- Gómez, Elbio Roberto, Una mirada a mi pueblo, El autor, Estación Sola, 2001.

- Grimaux de Gil, Margarita, Toponimia de Entre Ríos, Fundación de ciudades, Talaeres El Tribuno, Rosario del Tala, 1970.

- Guionet, Héctor N. La colonia San José, memorias entre ríos e imágenes, 1857 - 2000. El autor, 2000 
- Ibañez, Francisco, Evolución de la cartografía de Entre Ríos, en Presencia, № 1, Paraná, 1963

- Ibáñez, Francisco, Toponimia de Entre Ríos. La Tierra, el hombre y los hechos, Colección Entre Ríos № 8., Ed. Colmegna. Santa Fe, 1971

- II Censo nacional de población, 1895. (Impreso)

- Irigoyen, José Miguel, Toponimia guaraní de Corrientes, Instituto de Antropología "Juan B. Ambrosetti", Universidad de Concepción del Uruguay, 1994.

- Klocker Restano, Angela Maria y Dutruel, Susana Haller Maslein de, De Suiza a Entre Ríos: testimonios de una comunidad pionera, Colonia Nueva de Villa Urquiza, Editorial de Entre Ríos, 2006.

- Lappas, Alcibíades, Anarcasis Lanús, un hijo de Entre Ríos al servicio del país, revista Ser, N²2, C. del Uruguay, 1981.

- Leguizamón, Martiniano, Hombre y cosas que pasaron, J. Lajouane y Cía., Editores, Bs. As., 1926.

- Leguizamón, Martiniano, Recuerdos de la tierra, Ediciones Mar Océano, Bs. As. 1957.

- López Bréard, Miguel Raúl, Diccionario folklórico guaranítico, Moglia Ed., Corrientes, 2004.

- López de Borche, Celia Gladys, Historia Integral de Villa Mantero, Tomo I, Ediciones Gená, C. del Uruguay, 1993.

- López de Borche, Celia Gladys, Origen, desarrollo y ocaso de una colonia modelo, Museo u archivo histórico regional de la colonia judía, Villa Domínguez, Serie III. № 6, C. del Uruguay, 1986.

- López, Florencio, Toponimia de Entre Ríos: vigencia aborigen, EMEDE, C. del Uruguay, 1980.

- Luis Luján, Ceibas, tierra grandiosa - Crónicas del país de los matreros, Ensayo, Ediciones Del Clé, Paraná, 2007. 
- Maidana, Walter David y Bessón, Ariel Ramón, Durandó, historia de una comunidad, Los autores, Colón, 2006.

- Martínez, Benigno T., Historia de la Provincia de Entre Ríos, 3 T. Ediciones de 1900,1910 y 1920.

- Moretti, Cristina J. de, Hacia una Toponimia Normalizada. Trabajo presentado en noviembre de 1993, en las 1ras. Jornadas del Litoral sobre Toponimia, en Santa Fe capital.

- Muñoa Marcó, Ricardo, Elizaincín, Fermín Jorge, García Uriburu, Fernando, Izaguirre, Héctor César y Domìnguez Soler, Susana T. P. de, Los vascos en Entre Ríos, Ed. De Entre Ríos, 2001.

- Murature de Badaracco, María del Carmen y Rourich, Gabriel A. Toponimia histórica y fitotoponimia del Departamento Victoria, Segundas Jornadas del Litoral sobre Toponimia, Universidad Nacional del Nordeste, Resistencia, 1994.

- $\quad$ Neira, Miguel Julio, Rieles de Entre Ríos, Ediciones del Clé, Paraná, 2013.

- Notthoff, Delia Ester, Suárez, María del Rocío y Lound, Silvina María, Simientes del ayer. Villa Larroque, Centro de Archivo e Investigaciones Históricas de Larroque, 2007.

- Pandiani de Chemín, Magdalena y Gabás Walkiria, Historia Elemental de Entre Ríos, MC Ediciones, Paraná, 1992.

- Pérez Colman, César Blas, Historia de Entre Ríos, Época colonial (1520 1810), 3 T. Imprenta de la Provincia, Paraná, 1936 - 1937.

- Pérez Colman, César Blas, Toponimia entrerriana (Revista Universitaria, a. 1, v. 1 № 4-5, p. 4-6, oct. Nov. 1925)

- Piaggio, Enrique Ángel, Evocacones del ayer, Gualeguaychú, 1989.

- Poenitz, Alfredo J. Erich, La ocupación espacial del departamento Concordia (1810 - 1880), en Cuadernos de Estudios Regionales, № 6, 1983, Instituto Regional de Investigaciones Científicos - Culturales, Concordia. 
- $\quad$ Reula, Filiberto, Historia de Entre Ríos, 3 T., Castellví, Santa Fe, 1969.

- Rona, José Pedro, Nuevos elementos acerca de la lengua charrúa, Universidad de la República, Montevideo, 1964.

- Rondán, Damián Gustavo, Toponimia del departamento Paraná, Entre Ríos, Argentina, trabajo presentado en las II Jornadas de toponimia en la UNNE, Resistencia, Chaco - 1994. Aumentado en 2007.

- Sastre, Marcos, El Tempe argentino, impresiones y cuadros del Paraná, Consejo Nacional de Educación, Bs. As., 1938.

- Schepens, Eugene, Colonización Flamenca en Villaguay, Entre Ríos, Argentina, Villaguay, 2007.

- Segura, Juan José Antonio, Historia de Nogoyá, T. I: desde los orígenes hasta 1821, Editorial de la Mesopotamia, Paraná, 1972.

- Trossero, Oscar O. R., Costa Grande... historias del pago, Editorial de Entre Ríos, Paraná, 2001.

- Udaondo, Enrique, Significado de la nomenclatura de las estaciones ferroviarias de la República Argentina, Ministerio de Obras Públicas, Bs. As., 1942. Varini, César Manuel y Eguiguren, María Selva Ruth, Norte entrerriano, Museo Regional Camila Quiroga № 36, Chajarí, 1995.

- Varini, César Manuel, Efemérides Chajarenses, 2da. Edición, Municipalidad de Chajarí, 1980.

- Varini, César Manuel, La Matilde, Museo Regional Camila Quiroga N 10, Chajarí, 1990.

- Varini, César Manuel, Las colonias oficiales del departamento Federación, Museo Regional Camila Quiroga N¹1, Chajarí, 1991.

- Varini, César Manuel, Orígenes de San Jaime de la Frontera, S. J. de la Frontera, 1990 
- Varini, César Manuel; Eguiguren de Varini, María Selva Ruth. Toponimia federaense En: Estudios Regionales, Facultad de Humanidades, Universidad Nacional de Misiones, Volumen 6, Posadas, 1994.

\section{Publicaciones electrónicas en línea}

- El Patrimonio Histórico Arquitectónico de la Provincia de Entre Ríos, en http://www.colegioarquitectos.org.ar/ 23 octubre 2013.

- http://aldeasaltoentrerios.com.ar/24/7/13

- http://cronicasehistoriasferroviarias.blogspot.com.ar/2013/01/enciclopedi a-ferroviaria.

- http://dpvfederal.es.tl/

- http://es.wikipedia.org/wiki/Anexo:Islas_del_r\%C3\%ADo_Uruguay

- http://escuelasytrenestala.blogspot.com.ar

- http://ferrocarrilentrerriano.blogspot.com.ar

- http://kehilalinks.jewishgen.org/basavilbaso/pdf/basavilbaso_en1932jacob oglushankov.pdf

- http://laisladelta.com/foro

- http://puertocurtiembre.blogspot.com.ar/.

- http://responde.org.ar/sitio/. Acceso: 03/12/2014.

- http://sanjosedefeliciano.blogspot.com.ar/: Juan Ramírez

- http://soymosquero.blogspot.com/

- http://villaelisa.gov.ar/descargas/historiadevillaelisa.pdf

- http://www.alvarezdaneri.com.ar/gualeguaychu/rio-gualeguaychu-unpoco-de-historia.htm

- http://www.bassoenlared.com.ar/historia/hDownFrameBasso1.htm $20 / 8 / 2013$

- $\quad$ http://www.cacw.com.ar/ (Alemanes del Volga) 
- http://www.chasque.net/frontpage/relacion/0207/charrua.htm 20/8/2013

- http://www.comunidadargentina.org.ar/seccion-1819/entre-rios.aspx

- http://www.costaflorentino.com/puerto.swf (Historia de Pueblo General Alvear, por Marina Cecilia Meccia) 21-10-13.

- http://www.diamantedigital.com.ar/atractivo/regAtr/85/ficha_atractivo.ht $\mathrm{ml} 24 / 7 / 13$

- http://www.elalmanaque.com/santoral

- http://www.eldiaonline.com/historias-de-familia/ 1 de noviembre de 2013.

- http://www.eldiaonline.com/leyendas-de-gualeguaych/ - Acceso 10/10/13

- http://www.elparanaysusaldeas.com.ar/default.asp?sec=6 24/7/13

- http://www.e-portalsur.com.ar/expedito/

- http://www.fca.uner.edu.ar/mapas/

- http://www.genealogiaentrerios.com/articulos/estudios/familias_pioneras _concordia.swf

- http://www.histarmar.com.ar/Puertos/PtoColoniaCelina.htm (puertos)

- http://www.isletasnoticias.com.ar/ 24/7/13

- http://www.lahueya.com.ar/index/argentina/entre\%20r/flofau.htm

- http://www.losconquistadores.gov.ar/1.php

- http://www.munialdea.gov.ar/index.php/site/historia.html - 1 de noviembre de 2013.

- http://www.oni.escuelas.edu.ar/2004/ENTRE_RIOS/598/lascoler.htm $3 / 8 / 13$

- http://www.oni.escuelas.edu.ar/olimpi98/Elmate/toponimia.htm

- http://www.paranacito.com/la-ciudad/historia.html

- http://www.puiggariweb.com.ar/historia-de-puiggari

- http://www.region-litoral.com.ar

- http://www.santopedia.com 
- http://www.taringa.net/posts/imagenes/2571597/Fotos-de-mi-viaje-aGeneral-Galarza.html

- http://www.viarural.com.ar/viarural.com.ar/agricultura/arbolesautoctonos/default.htm

- Jover Peralta, Anselmo, Almanaque del Banco de Seguros del Estado Montevideo, 1965, en http://letrasuruguay.espaciolatino.com/notas/guarinismos.htm.

- Juan D. Delius, en http://www.pampa-cordobesa.de/Renglon_M.pdf $16 / 10 / 45$

- Luis Luján en http://blogsdelagente.com/ceibas-tierra-grandiosa/

- Soares de Lima, Carlos. La Antigua Banda Oriental, Exposición en Casa de Residentes de Lavalleja, - 26 de marzo de 2009 en http:-www.patriada.com.uy-de-historia-la-banda-oriental-la-antigua-bandaoriental-. Agosto, 2013.

- Surraco, Jorge, Un viaje al país de Las Lechiguanas, en http://laboticadeldiablo.blogspot.com.ar/2012/01/un-viaje-al-pais-de-laslechiguanas-5.html

\section{Material cartográfico}

- Mapa de las Misiones de la Compañía de Jesús, por el P. José Quiroga, 1749, reproducción del P. Guillermo Furlong.

- Mapa confeccionado por Tomás de Rocamora (1782) Sala IX 35-1-5 exp. 27, Archivo General de la Nación.

- Carta de Entre Ríos, Dirección de Catastro, Entre Ríos, 1994. Escala 1:500.000 (Copia impresa AGER)

- Carta de la Provincia de Entre Ríos, varios departamentos, publicado por el gobierno de Entre Ríos, 1905, escala 1:200.000. (Original AGER) 
- Dirección Nacional de Estadísticas y Censos, Departamento Organización Censal. Planos de radios censales escolares. Departamento Diamante. Actualizado a 1970.

- Carta de la Provincia de Entre Ríos. Registro gráfico de las propiedades rurales. Departamento de Obras Públicas, Entre Ríos. 1927. Escala 1:200.000 (Original AGER)

- Carta topográfica de la República Argentina, IGM, levantamientos 1909, 1911, 1912 y 1914. Escala 1:50.000, Varias planchas impresas de localidades de Entre Ríos (Mapoteca AGER)

- Plano Topográfico Catastral de la Provincia de Entre Ríos, 1886, de Rígoli y Guzmán. (Original AGER)

- Carta de la Provincia de Entre Ríos, Circa 1970 (Copia heliográfica AGER)

- Plano Ludwig de la República Argentina, Oficina Cartográfica Ludwig, Bs. As. 1959

\section{Fuentes orales}

- Arcusin, Mario Ignacio, abogado, docente y periodista. Basavilbaso, entrevista, 31/01/14.

- Blanche, Julio, La Paz, historiador, entrevista, 17/09/13.

- Brumatti, Ricardo Luis, historiador, Diamante, 20/8/2013

- Cudine, Pablo, Victoria, investigador, junio 2013.

- De la Madrid, Silvia, docente, sobre la colonización judía, San Salvador General Campos. Varias consultas, junio - Julio, 2013-10-05

- Faure, Marcelo, La Paz, varias entrevistas, Junio - Agosto, 2013. 
- Fontana, Carolina Patricia, El Cimarrón, dpto.Federal, Maestra de la escuela $n^{\circ} 48$ de Conscripto Bernardi. 19/9/13

- Gallay, Omar, profesor de Geografía, entrevista, Concepción del Uruguay, junio 14, 2013

- Gauna, Gabriel Elías, Calabacilla, Concordia

- Giles, Rosa Isabel, Directora Escuela № 44 "1² de Mayo", Las Pajitas, Dpto. Villaguay, 10/9/13

- Harman, Ángel, profesor de Historia, Concepción del Uruguay, mayo junio 2013, varias comunicaciones vía internet.

- Hecker, Carlos Roberto, vecino de colonia Lucienville, entrevista, 24 de enero de 2104.

- Kaplan, Marta, profesora de Historia y escritora, Formosa, oriunda Villa San Marcial. Comunicaciones por correo electrónico, octubre 2013 y noviembre de 2013.

- Lell, Juan, Aldea Spatzencuter, entrevista, 7/8/13

- Luján, Luis, bibliotecario, escritor, Gualeguaychú, entrevista: 6 y 7 de noviembre 2013.

- Maidana, Walter David, historiador, Colón. Entrevista, julio 2013.

- Panizza, Mirta, Paraná - Las Moscas, entrevista, junio 2013

- Perroud, Raúl, Colonia El Cármen, departamento Colón, entrevista, junio 13 de 2013

- Pretto, Gladys, Paraná, 9 de diciembre de 2103.

- Rebot, Raúl, Salta, oriundo de colonia El Pantanoso, Dpto. Uruguay. Comunicación por correo electrónico, 17/10/13.

- Romani, Roberto, oriundo de Larroque, 13 de diciembre de 2013. 
- Roskop, Alejandro Martín, Maciá, 30/08/13

- Roskop, Alejandro Martín, Maciá, 30/8/13 .

- Rougier, David, Villa Elisa, comunicaciones vía internet, junio 13 de 2013 y noviembre de 2013.

- Tramontina, Olga, docente de nivel secundario, Concordia, comunicación, $11 / 9 / 13-$

- Yañez, Mario Enrique, Feliciano, entrevista, 26/6/13

\section{$\underline{\text { Repositorios }}$}

- Archivo General de Entre Ríos. Fondo gobierno: series Tierras, Leyes y decretos, Colonias oficiales, Municipios y juntas de gobierno.

- Archivo General de Entre Ríos. Cartografía del Consejo General de Educación.

- Museo de Ciencias Naturales y Antropológicas “Prof. Antonio Serrano”.

- Biblioteca Provincial de Entre Ríos.

- Archivo personal de Magdalena Pandiani, Paraná.

- Archivo General de Entre Ríos. Fondo de Geodesia y Topografía de la Dirección de Catastro.

- Archivo de la Dirección General de Relaciones Municipales

- Archivo de la Dirección de Juntas de Gobierno. 


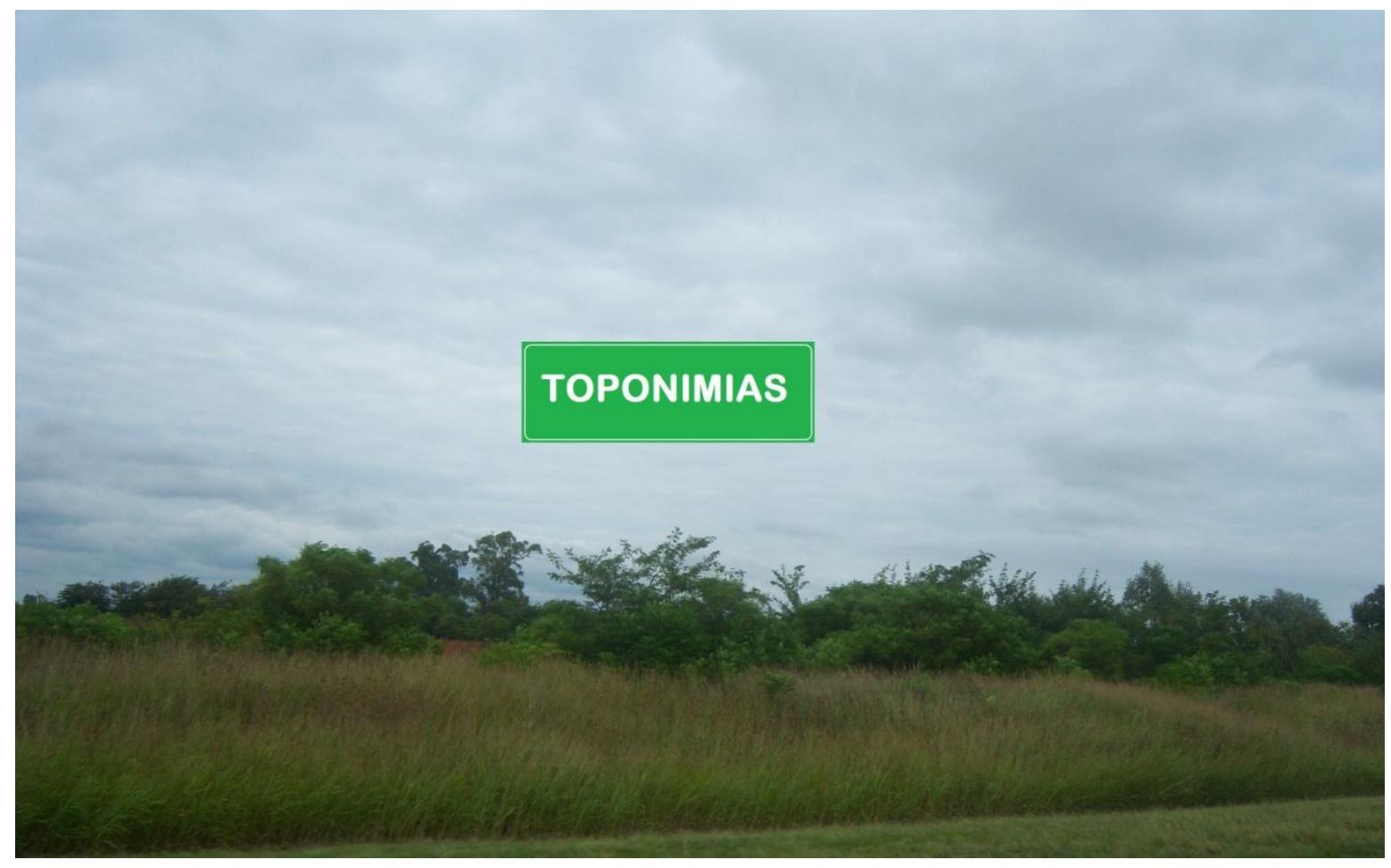

ANEXOS I

\section{Cuadros estadísticos de los topónimos}




\section{Fitotopónimos}

Total de nombres: 174

(El número indica la frecuencia de cada nombre)

$\begin{array}{llllll}\text { Abrojo } & 1 & \text { Durazno } & 3 & \text { Quebracho } & 8 \\ \text { Achira } & 7 & \text { Espinillo } & 4 & \text { Ramada } & 1 \\ \text { Ají } & 1 & \text { Guayabo } & 2 & \text { Sarandí } & 4 \\ \text { Algarrobo } & 5 & \text { Hinojo } & 1 & \text { Sauce } & 39 \\ \text { Árboles } & 1 & \text { Laurel } & 3 & \text { Tacuaras } & 2 \\ \text { Ayuí } & 2 & \text { Maciegas } & 2 & \text { Tala } & 14 \\ \text { Berros } & 1 & \text { Mandisoví } & 4 & \text { Tases } \\ \text { Calabacillas } & 1 & \text { Molle } & 2 & \text { Timbó } & 1 \\ \text { Cañas } & 2 & \text { Nancay } & 1 & \text { Tuna } & 3 \\ \text { Ceiba } & 5 & \text { Ombú } & 3 & \text { Ubajay } & 6 \\ \text { Ceibo } & 5 & \text { Pajonal } & 4 & \text { Viraró } & 1 \\ \text { Chañar } & 9 & \text { Palmar } & 3 & \text { Yatay } & 1 \\ \text { Chilca } & 5 & \text { Paraíso } & 2 & \text { Yeruá } & 2 \\ \text { Curupí } & 4 & \text { Porongo } & 1 & \text { Yuquerí } & 4\end{array}$




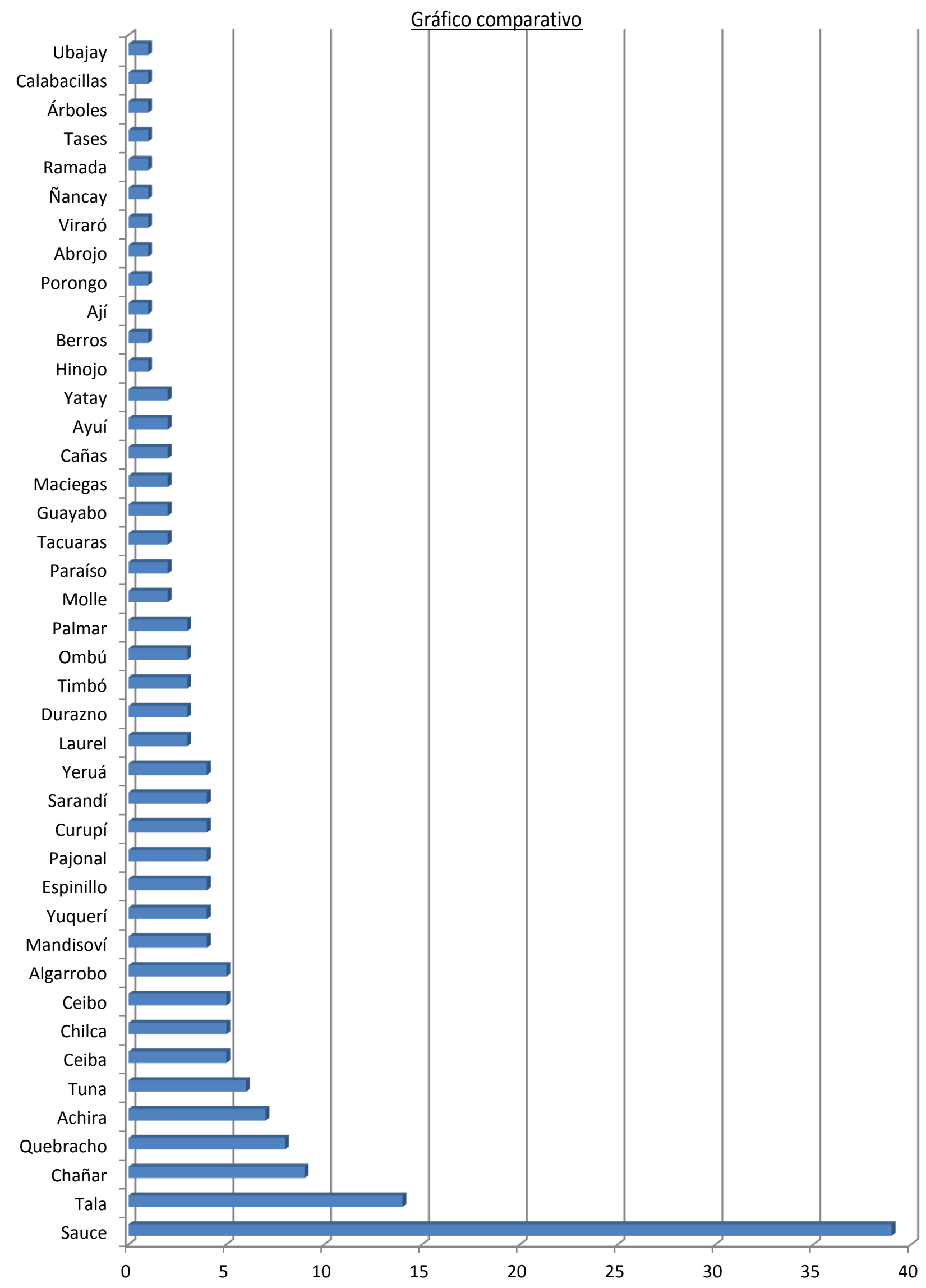




\section{Zootopónimos}

Total de nombres: 64

(El número indica la frecuencia de cada nombre)

$\begin{array}{llllll}\text { Aguará } & 1 & \text { Gallo } & 1 & \text { Pospós } & 1 \\ \text { Animal } & 1 & \text { Garzas } & 1 & \text { Potrillo } & 1 \\ \text { Arañas } & 1 & \text { Gato } & 2 & \text { Rana } \\ \text { Bayos } & 1 & \text { Lechiguana } & 2 & \text { Ratón } & 1 \\ \text { Bellaco } & 3 & \text { Lobo } & 2 & \text { Redomón } & 1 \\ \text { Buey } & 1 & \text { Loros } & 1 & \text { Taraguy } & 1 \\ \text { Calandria } & 1 & \text { Moscas } & 3 & \text { Tatutí } & 2 \\ \text { Carpincho /Carpinchori } & 2 & \text { Mulas } & 6 & \text { Tigre / Tigrera } & 7 \\ \text { Cavayú Cuatiá } & 1 & \text { Novillos } & 1 & \text { Toro } & 1 \\ \text { Chajá / Chajarí } & 3 & \text { Paloma } & 2 & \text { Víboras } & 1 \\ \text { Cimarrón } & 1 & \text { Perdices } & 3 & \text { Vizcacha } & 2 \\ \text { Cisne } & 1 & \text { Pescado } & 2 & & \\ \text { Dorado } & 1 & \text { Pingo } & 1 & & \end{array}$




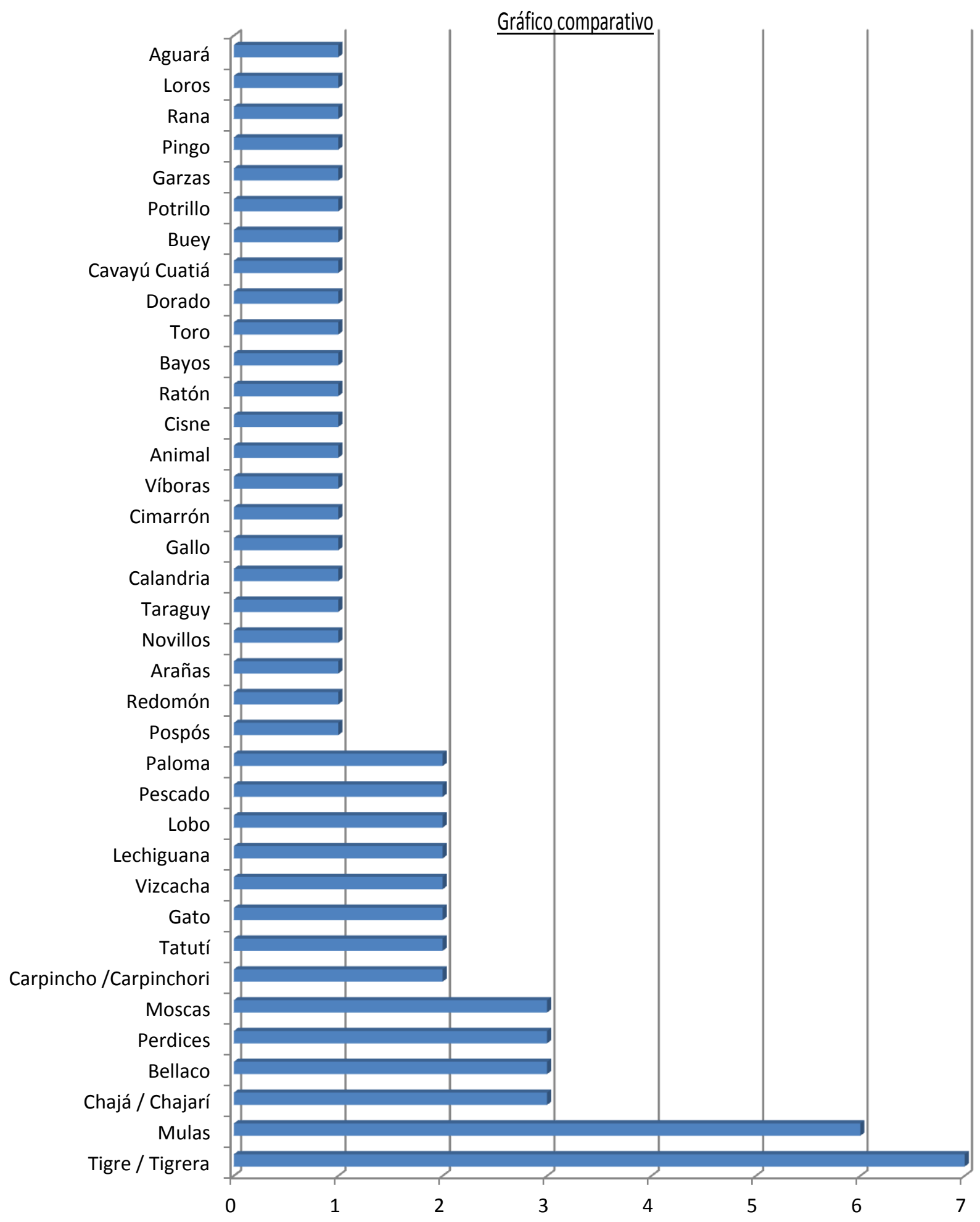




\section{Fisiotopónimos}

Total de nombres: 116

(El número indica la frecuencia de cada nombre)

$\begin{array}{lllllr}\text { Albardón } & 1 & \text { Ensenada } & 1 & \text { Piedras } & 6 \\ \text { Barrancoso } & 2 & \text { Hervidero } & 1 & \text { Potrero } & 2 \\ \text { Boca chica } & 1 & \text { Hondo } & 3 & \text { Pozos } & 2 \\ \text { Brazo } & 4 & \text { Ibucuy } & 3 & \text { Puntas } & 1 \\ \text { Centella } & 1 & \text { Isleta } & 3 & \text { Rabón } & 2 \\ \text { Cerro / Cerrito } & 5 & \text { Itapé } & 2 & \text { Ramblón / Ramblones 6 } \\ \text { Chiqueros } & 2 & \text { Laguna del Pescado } & 2 & \text { Rayos } & 2 \\ \text { Correntoso } & 1 & \text { Manantiales } & 3 & \text { Rincón } & 3 \\ \text { Costa de Nogoyá } & 1 & \text { Médanos } & 3 & \text { Salto } & 2 \\ \text { Costa Grande } & 1 & \text { Pantanoso } & 2 & \text { Santo Grande } & 1 \\ \text { Costa Uruguay } & 2 & \text { Paso } & 28 & \text { Tamberas } & 2 \\ \text { Cuchilla } & 2 & \text { Pedernal } & 2 & \text { Tiguá } & 1 \\ \text { Cuevas } & 1 & \text { Pehuajó } & 3 & \text { Toscas } & 1 \\ \text { Delta } & 1 & \text { Picada } & 1 & \text { Yeso } & 3\end{array}$




Toponimias de Entre Ríos, síntesis y actualización

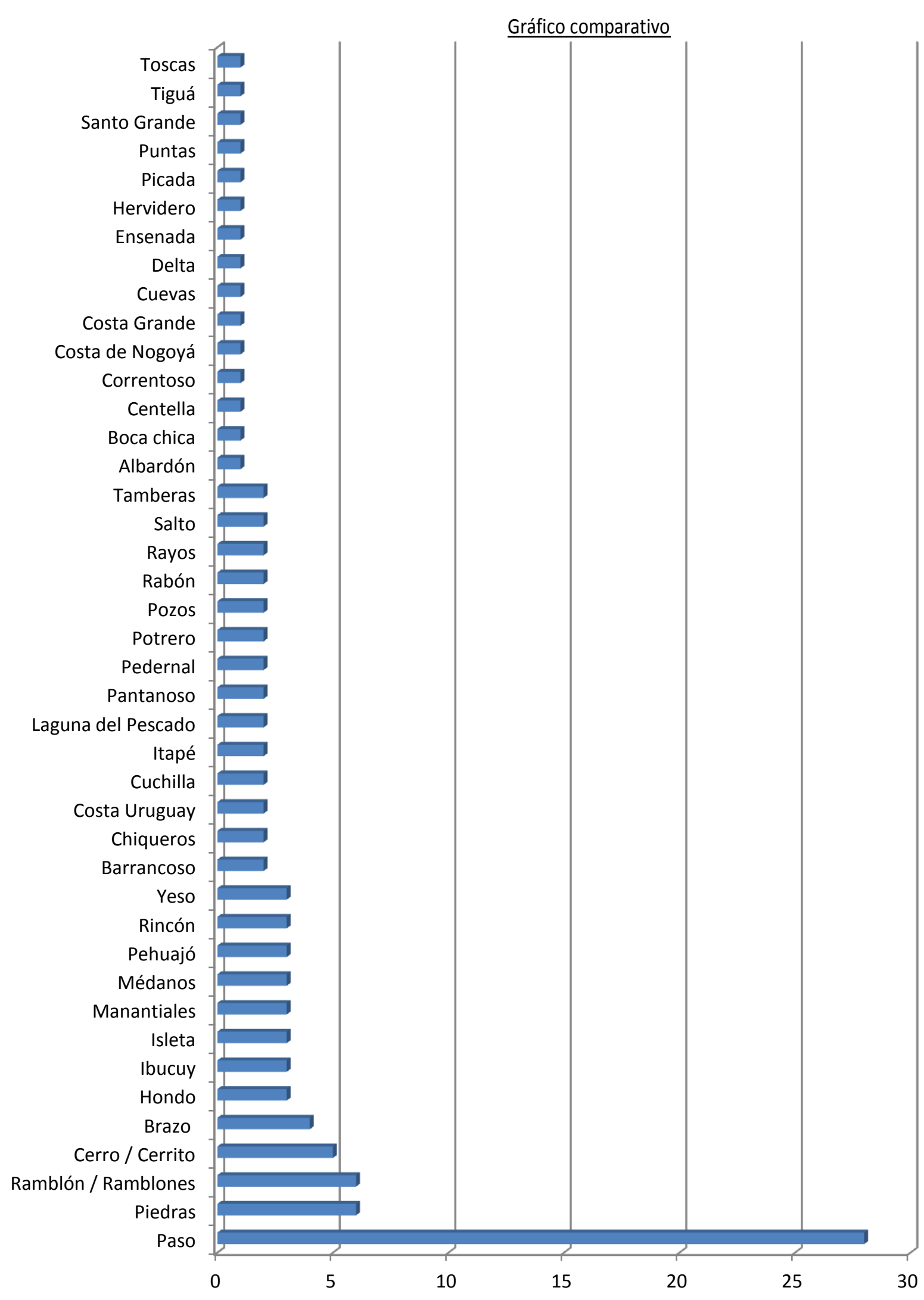




\section{Fisiotopónimos}

Total de nombres: 311

(El número indica la frecuencia de cada nombre)

\begin{tabular}{|c|c|c|c|c|}
\hline Adelina & 1 & Camps & 1 & Don Cristóbal \\
\hline Alarcón & 1 & Cañada Sánchez & 1 & Don Gonzalo \\
\hline Alberdi & 1 & Caraballo & 2 & Doña Justa \\
\hline Albornoz & 1 & Carbajal & 1 & Dos Hermanas \\
\hline Alcaraz / Alcaracito & 10 & Cardoso & 1 & El Obispo \\
\hline Almacén Iglesias & 1 & Catalina & 1 & Embarcadero Fernández \\
\hline Almada & 1 & Cattáneo & 1 & Enrique Carbó \\
\hline Altamirano & 3 & Cazés & 1 & Escriña \\
\hline Alvear & 2 & Ceballos & 1 & Espino \\
\hline Antelo & 1 & Celina & 1 & Faustino Parera \\
\hline Antonio Tomás & 3 & Clara & 2 & Febre \\
\hline Antoñico & 1 & Colodomiro Ledesma & 1 & Feliciano \\
\hline Aquino & 1 & Colón & 2 & Fernández \\
\hline Aranguren & 1 & Colonia Duportal & 1 & Fidanza \\
\hline Arévalo & 1 & Colonia Elía & 2 & Filomena \\
\hline Arrúa & 1 & Conscripto Bernardi & 1 & Florentino Urrutia \\
\hline Atencio & 3 & Constanza & 1 & Freitas \\
\hline Avellaneda & 1 & Coraceros & 1 & García \\
\hline Avigdor & 1 & Correa & 1 & Garibaldi \\
\hline Báez & 1 & Crespo & 2 & Gauchos \\
\hline Baltazar & 1 & Criolla & 1 & General Almada \\
\hline Barú & 2 & Cupalén & 3 & General Campos \\
\hline Basavilbaso & 2 & De la China & 1 & General Galarza \\
\hline Basualdo & 2 & Del Carmen & 1 & General Güemes \\
\hline Baylina & 1 & Del Cordobés & 1 & General Ramírez \\
\hline Belgrano & 2 & Del Cura & 1 & General Roca \\
\hline Berduc & 1 & Del Doctor & 1 & Gilbert \\
\hline Bergara & 2 & Del Fraile & 1 & Gobernador Echagüe \\
\hline Berisso & 1 & Del Francés & 1 & Gobernador Mansilla \\
\hline Bermúdez & 1 & Del Paraguayo & 2 & Gobernador Sola \\
\hline Bernachea & 1 & Del Pillo & 1 & Godoy \\
\hline Berones & 1 & Del Portugués & 1 & González Calderón \\
\hline Betbeder & 1 & Delgado & 1 & Guerrero \\
\hline Brugo & 1 & Diego & 1 & Gutierrez \\
\hline Burgos & 2 & Diego López & 2 & Hambís \\
\hline Calá & 1 & Dolores & 1 & Hasenkamp \\
\hline
\end{tabular}




\begin{tabular}{|c|c|c|c|c|}
\hline Herminio J. Quirós & 1 & Mármol & 1 & Puerto Ruiz \\
\hline Hernandarias & 3 & Martín & 1 & Puiggari \\
\hline Herrera & 1 & Martín García & 1 & Querencio \\
\hline Hocker & 2 & Martínez & 2 & Racedo \\
\hline Holt & 1 & Matilde & 1 & Rivadavia \\
\hline Hugues & 1 & Máximo Castro & 1 & Rivarola \\
\hline Inés Dorrego & 1 & Mencho & 1 & Robledo \\
\hline Ingeniero Sajaroff & 1 & Merou & 1 & Rocamora \\
\hline Irazusta & 1 & Montiel & 4 & Rosita \\
\hline Jacinta & 2 & Montoya & 3 & Sagastume \\
\hline Jaime & 1 & Morán & 1 & Salinas \\
\hline José Artigas & 1 & Moreno & 2 & San Martín \\
\hline Juan Correntino & 1 & Moreyra & 6 & Sandoval \\
\hline Juan Jorge & 1 & Mosqueira & 1 & Sauce de Luna \\
\hline Juan P. Garat & 1 & Olegario V. Andrade & 1 & Sauce Montrull \\
\hline Juan V. Morán & 1 & Ormachea & 1 & Seguí \\
\hline La Santiagueña & 1 & Ortiz & 1 & Sir Leonard Cohen \\
\hline La Sarita & 1 & Osuna & 1 & Sosa \\
\hline Lamarca & 1 & Osvaldo Magnasco & 1 & Tabossi \\
\hline Landa & 1 & Otero & 1 & Tezanos Pinto \\
\hline Larroque & 1 & Pairirí & 1 & Toledo \\
\hline Lavagna & 1 & Palavecino & 1 & Torres \\
\hline Lazo & 1 & Pancho & 2 & Unzué \\
\hline Leguizamón & 1 & Parera & 1 & Uranga - Silvestre Begnis \\
\hline Líbaros & 1 & Paso Birrinchín & 1 & Urdinarrain \\
\hline López & 1 & Paso Castro & 1 & Urquiza \\
\hline Los Porteños & 1 & Paso Duarte & 1 & Vázquez \\
\hline Lucas & 5 & Paso Medina & 1 & Venerato \\
\hline Lucas González & 1 & Paso Ortiz & 1 & Vera \\
\hline Lucienville & 1 & Pastor Britos & 1 & Viale \\
\hline Luis Ferreyra & 1 & Pedro Bustos & 1 & Villa Domínguez \\
\hline Luis L. Etchevehere & 1 & Peña & 1 & Villa Elisa \\
\hline Lynch & 1 & Pereyra & 1 & Villa Fontana \\
\hline Maciá & 1 & Perper & 1 & Villegas \\
\hline Manso & 1 & Perucho Verna & 1 & Viuda Rosa \\
\hline Mantero & 1 & Piagguio & 1 & Vizcaíno \\
\hline María Grande / Chico & 6 & Piloto Ávila & 1 & Walter Moss \\
\hline María Luisa & 1 & Planes & 1 & Zenón Roca \\
\hline
\end{tabular}




\section{Hagiotopónimos}

Total de nombres: 81

(El número indica la frecuencia de cada nombre)

$\begin{array}{llllll}\text { Aldea Asunción } & 1 & \text { San Isidro } & 1 & \text { San Salvador } & 3 \\ \text { Concepción } & 2 & \text { San Jaime } & 1 & \text { San Simón } & 1 \\ \text { Crucecitas } & 6 & \text { San Jorge } & 1 & \text { San Víctor } & 1 \\ \text { De la Cruz } & 1 & \text { San José } & 7 & \text { Santa Anita } & 2 \\ \text { La Paz } & 1 & \text { San Juan } & 3 & \text { Santa Celia } & 1 \\ \text { La Virgen } & 1 & \text { San Julián } & 2 & \text { Santa Clara } & 1 \\ \text { San Agustín } & 1 & \text { San Justo } & 2 & \text { Santa Elena } & 2 \\ \text { San Alejo } & 1 & \text { San Lorenzo } & 4 & \text { Santa Juana } & 2 \\ \text { San Anselmo } & 1 & \text { San Luis } & 1 & \text { Santa Luisa } & 1 \\ \text { San Antonio } & 6 & \text { San Marcial } & 1 & \text { Santa Margarita } & 1 \\ \text { San Bárbara } & 1 & \text { San María } & 1 & \text { Santa María } & 1 \\ \text { San Benito } & 1 & \text { San Miguel } & 4 & \text { Santa Rosa } & 2 \\ \text { San Ernesto } & 1 & \text { San Pascual } & 1 & & \\ \text { San Genaro } & 1 & \text { San Pedro } & 3 & & \\ \text { San Gregorio } & 3 & \text { San Ramírez } & 1 & & \\ \text { San Gustavo } & 1 & \text { San Ramón } & 1 & \end{array}$




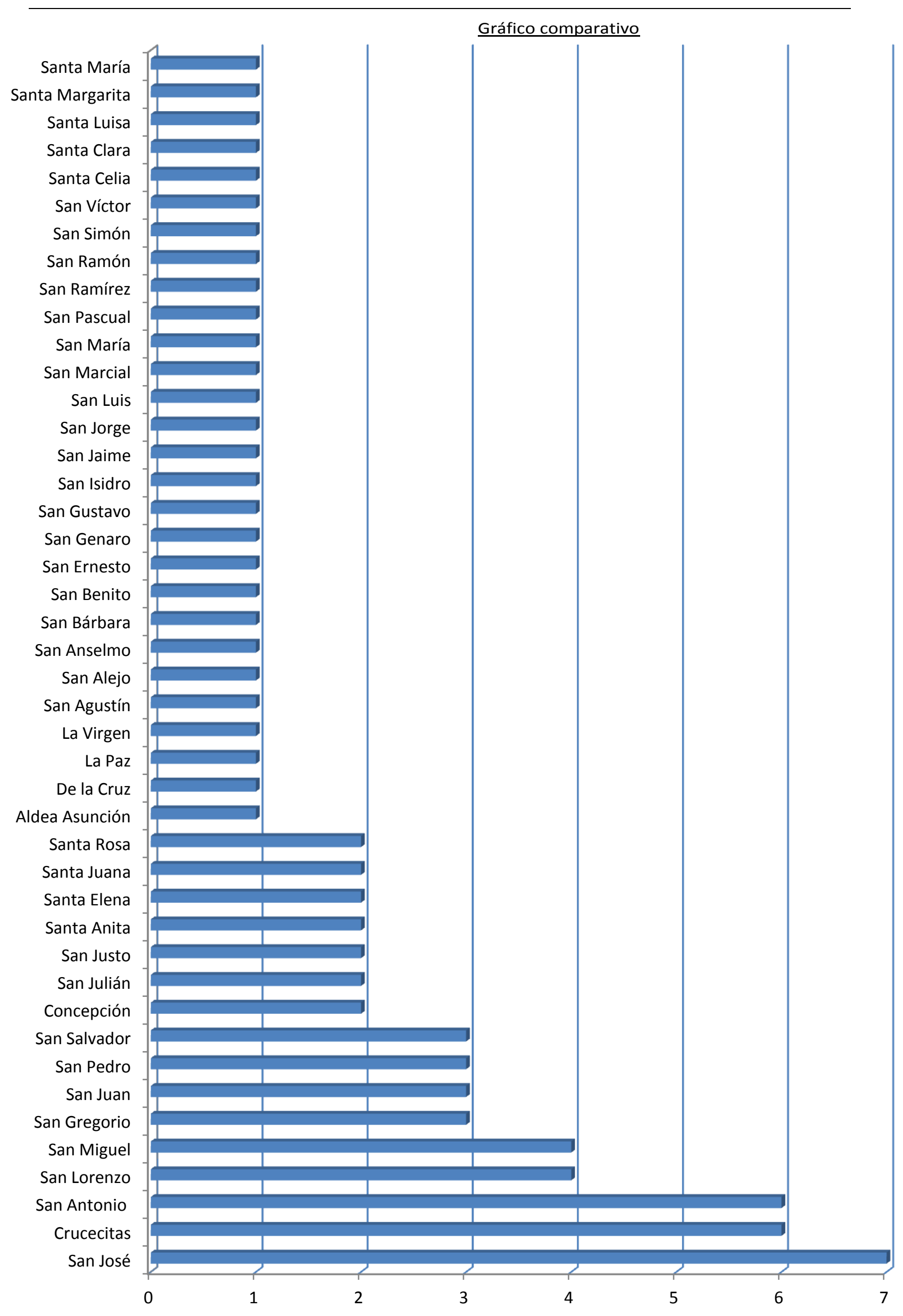




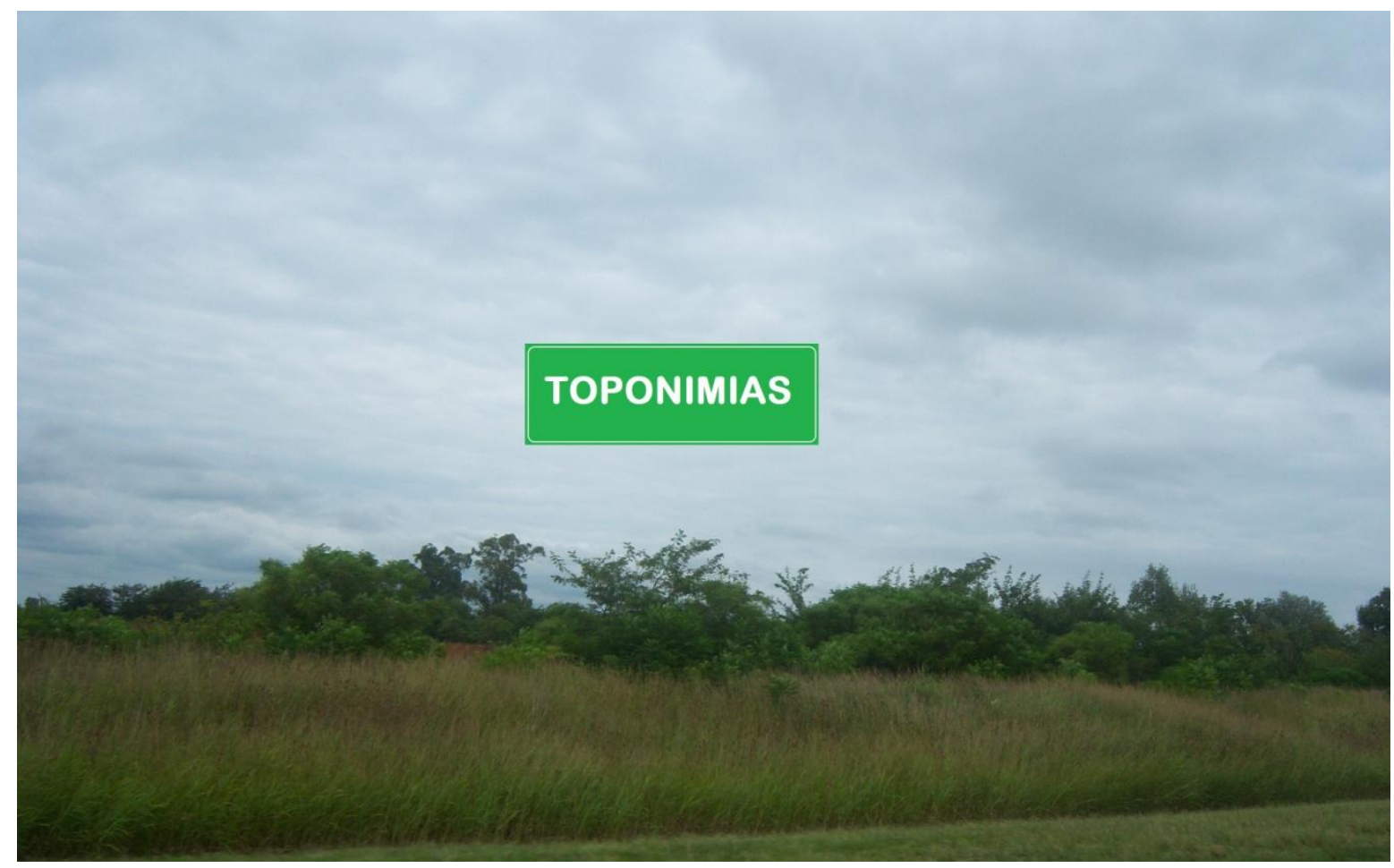

ANEXOS II

\section{Declaración de interés cultural}




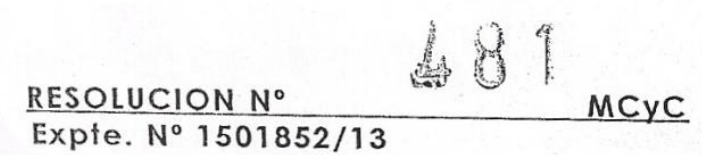

ONinistexio de Culusra y Comunicación

Gobiensio de Q̈ntre Trios

PARANÁ, 04 OCT 2013.

VISTO:

La gestión iniciada desde el Archivo General de Entre Ríos, dependiente de este Ministerio, y;

CONSIDERANDO:

Que a través de la misma solicita la declaración de Interés Cultural del Proyecto denominado "TOPONIMIAS DE ENTRE RÍOS, SÍNTESIS Y ACTUALIZACIÓN", que se lleva a cabo en conjunto con el Consejo Federal de Inversiones (CFI); Y

Que el citado proyecto se propone, entre otros objetivos, unificar la toponimia de las poblaciones, la orografía e hidrografía de la provincia a nivel de escala 1:500.000, contribuir al conocimiento de nuestros lugares como aporte a nuestra identidad, brindar material de uso educativo, reforzar los circuitos turísticos con información de interés, diseñar un sistema de localización geográfica mediante coordenadas geográficas; $y$

Que se afirma que al concluir el proyecto se dispondrá de una versión sintética, actualizada y ordenada de la toponimia entrerriana, resultado de la investigación de los diversos antecedentes obrantes en la bibliografía citada en el mencionado proyecto, y de la que surja en el proceso de investigación, así como de la cartografía de diverso origen; $y$

Que se indica asimismo, que el proyecto se insertaría dentro de la política de educación provincial, por cuanto posibilitará la /// 


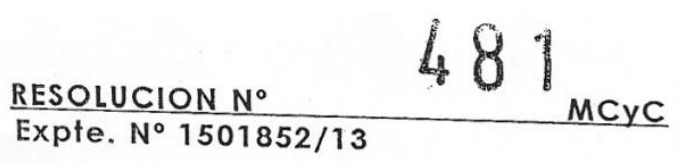

Ministexio de Gultusar y Comunicacion

Gobiemna de Grutre Rlos

//// producción de un material didáctico integral (textos, CD interactivos, videos soportes magnéticos, láminas, paginas web, entre otros), en cuanto hace referencia a la identidad de los entrerrianos, a través de acontecimientos históricos, la geografía, la cultura y las tradiciones que se manifiestan también en su toponimia, tanto de origen cultural como natural; $y$

Que por todo lo arriba expuesto, es que esta gestión ministerial entiende pertinente el apoyar esta iniciativa científica destinada a sistematizar los topónimos entrerrianos, constitutivos también de nuestro patrimonio cultural;

Por ello:

\section{EL MINISTRO DE CULTURA Y COMUNICACIÓN}

RESUELVE:

ARTículo $1^{\circ}$.- Declarar de Interés Cultural al Proyecto denominado "TOPONIMIAS DE ENTRE RÍOS, SÍNTESIS Y ACTUALIZACIÓN"; Ilevado adelante por el Profesor Rubén Isidoro BOURLOT, con la colaboración del Geólogo Juan Carlos BERTOLINI y de la. Arquitecta María Virginia ZABALEGUI, y teniendo como representante provincial al Profesor Juan Damían CAPDEVILA, en su carácter de pirector del Archivo General de Entre Ríos, auspiciago por el Consejo/Federal de Inversiones (CFI), de acuerdo a lo expresado en los Considerandos.

ARTí́CULO $2^{\circ}$ - Comunicar, public or y archivar.

aml

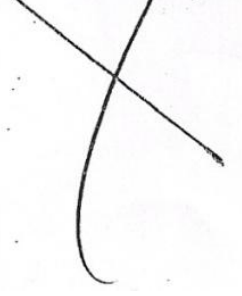


